Review

\title{
Recent Progress in Fluorescent Imaging Probes
}

\author{
Yen Leng Pak, K. M. K. Swamy and Juyoung Yoon* \\ Department of Chemistry and Nano Sciences, Ewha Womans University, Seoul 120-750, Korea; \\ E-Mails: xiaobai080488@yahoo.com (Y.L.P.); kmkswamy@yahoo.com (K.M.K.S.) \\ * Author to whom correspondence should be addressed; E-Mail: jyoon@ewha.ac.kr; \\ Tel.: +82-2-3277-2400; Fax: +82-2-3277-2384.
}

Academic Editors: Frances S. Ligler and Brandy J. Johnson

Received: 16 August 2015 / Accepted: 17 September 2015 / Published: 22 September 2015

\begin{abstract}
Due to the simplicity and low detection limit, especially the bioimaging ability for cells, fluorescence probes serve as unique detection methods. With the aid of molecular recognition and specific organic reactions, research on fluorescent imaging probes has blossomed during the last decade. Especially, reaction based fluorescent probes have been proven to be highly selective for specific analytes. This review highlights our recent progress on fluorescent imaging probes for biologically important species, such as biothiols, reactive oxygen species, reactive nitrogen species, metal ions including $\mathrm{Zn}^{2+}, \mathrm{Hg}^{2+}, \mathrm{Cu}^{2+}$ and $\mathrm{Au}^{3+}$, and anions including cyanide and adenosine triphosphate (ATP).
\end{abstract}

Keywords: fluorescent probes; imaging probes; fluorescent chemosensors; fluorescent chemosensors for biothiols; fluorescent chemosensors for ROS; fluorescent chemosensors for metal ions

\section{Introduction}

The recognition of biologically and environmentally important species in addition to imaging them has been an important research task in recent years [1-3]. Compared to other analytical tools, fluorescent probes have several merits, including simplicity, low detection limit, and most importantly, cell-imaging with the aid of confocal microscopy [4-10]. Recent developments on near IR (NIR) fluorescent probes and two-photon fluorescent probes have enabled the visualization of biologically important analytes in the mouse and in tissues [11-13]. 
Traditional approaches using molecular recognition and host-guest chemistry have been adopted to design fluorescent chemosensors for many years [14]. de Silva [15], Czarnik [16,17] et al. reported pioneering works in this regards. Earlier works on fluorescent chemosensors further extended their scopes for various biologically important analytes. The most dramatic change in this field was the appearance of reaction-based fluorescent probes, so-called chemodosimeters [18-20], which react with specific analytes, resulting in irreversible optical changes, yet, with usually better selectivity than those originating from host-guest chemistry.

In this review, we will cover our recent contributions to this exciting topic. This review highlights the recent progress on fluorescent imaging probes for biologically important species, such as biothiols, reactive oxygen species, reactive nitrogen species, metal ions including $\mathrm{Zn}^{2+}, \mathrm{Hg}^{2+}, \mathrm{Cu}^{2+}$ and $\mathrm{Au}^{3+}$, and anions including cyanide and ATP.

\section{Fluorescent Probes on Biologically Important Species}

\subsection{Fluorescent Probes for Biothiols}

Biothiols, such as cysteine (Cys), homocysteine (Hcy) and glutathione (GSH), play key roles in physiological systems. It is known that abnormal intracellular thiols are closely related to various health problems. Accordingly, fluorescent probes for these biothiols have attracted great attention in recent years [21].

A few years ago, our group introduced fluorescein-based probe $\mathbf{1}$ as a fluorescent probe for biological thiols (Figure 1) [22]. As shown in Figure 1, the spiro lactone ring opening occurred upon the addition of biothiols (GSH, Cys and Hcy) to the $\alpha, \beta$-unsaturated ketone, resulting in fluorescence enhancement $\left(\lambda_{\max }=520 \mathrm{~nm}\right)$ in HEPES buffer $\left(20 \mathrm{mM}, \mathrm{pH} 7.4,1 \% \mathrm{CH}_{3} \mathrm{CN}\right)$. To monitor thiols in living cells and organisms, murine P19 embryonic carcinoma cells and a three-day-old zebrafish were incubated with 1. Strong fluorescence enhancement was observed inside the cells and zebrafish. When zebrafish and cells were pretreated with a trapping reagent of thiols, $N$-methylmaleimide (NMM), significant fluorescence quenching was observed, which indicates that probe 1 images biothiols, especially GSH, present in the cells or zebra fish.
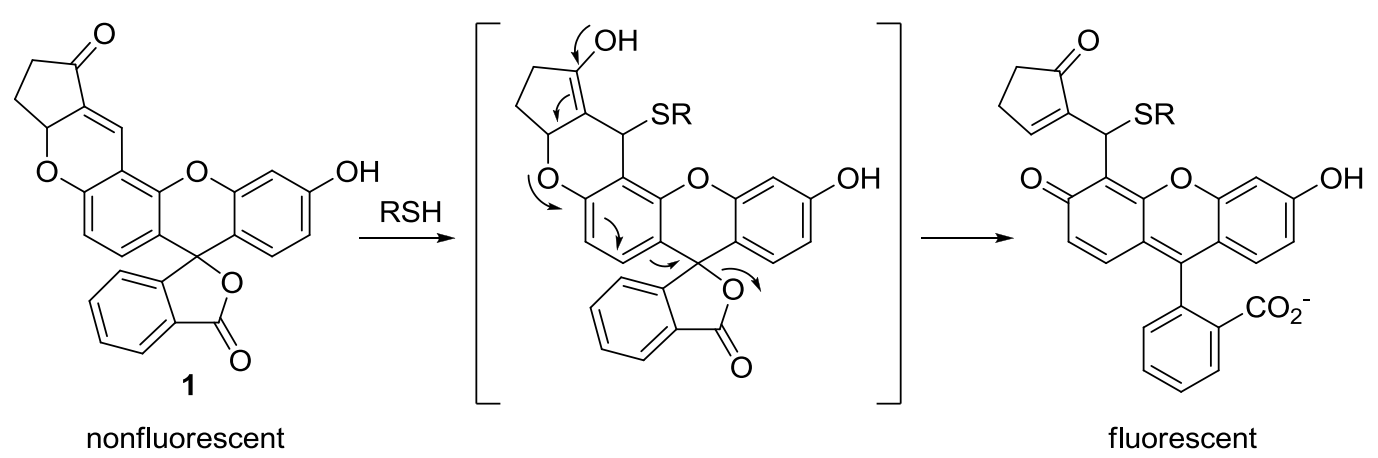

Figure 1. Reaction scheme for biothiol selective probe $\mathbf{1 .}$

Non-selective biothiol probes can usually image GSH, the most abundant biothiol in cells. For Cys and Hcy, selective recognition of these biothiols is certainly required, which is quite a challenging task due to the structural similarity of Cys and Hcy. In 2011, a pioneering work was reported by 
Strongin's group, in which an $\alpha, \beta$-unsaturated carbonyl recognition unit was first utilized to discriminate Cys from Hcy with a kinetically favored 7-membered ring formation [23].

We recently applied Strongin's strategy to a new near-infrared (NIR) cyanine-based probe 3 (CyAC), which can selectively sense Cys over Hcy and GSH (Figure 2) [24]. In this study, we proposed a new strategy to induce distinct optical changes in the cyanine system. As shown in Figure 2, the absorption and emission maximums of hydroxy cyanine CyAE2 and its keto form 2 ' can be distinctively different with the modulation of polymethine $\pi$-electron systems. Accordingly, the title probe $\mathbf{3}$ containing an acrylate group as a trigger moiety for Cys can show similar large shifts in its absorption and emission spectra (from 770 to $515 \mathrm{~nm}$ for absorption and from 780 to $570 \mathrm{~nm}$ for emission) after adduct-cyclization reaction with Cys. Probe $\mathbf{3}$ was applied to the biological imaging of Cys in MCF-7 cells grown in glucose-free Dulbecco's modified Eagle medium. During glucose deprivation, the intracellular Cys level is known to be significantly increased. Large fluorescence enhancement at $590 \mathrm{~nm}$ and a dramatic fluorescence decrease in the NIR region (760-855 nm) was observed under this condition.
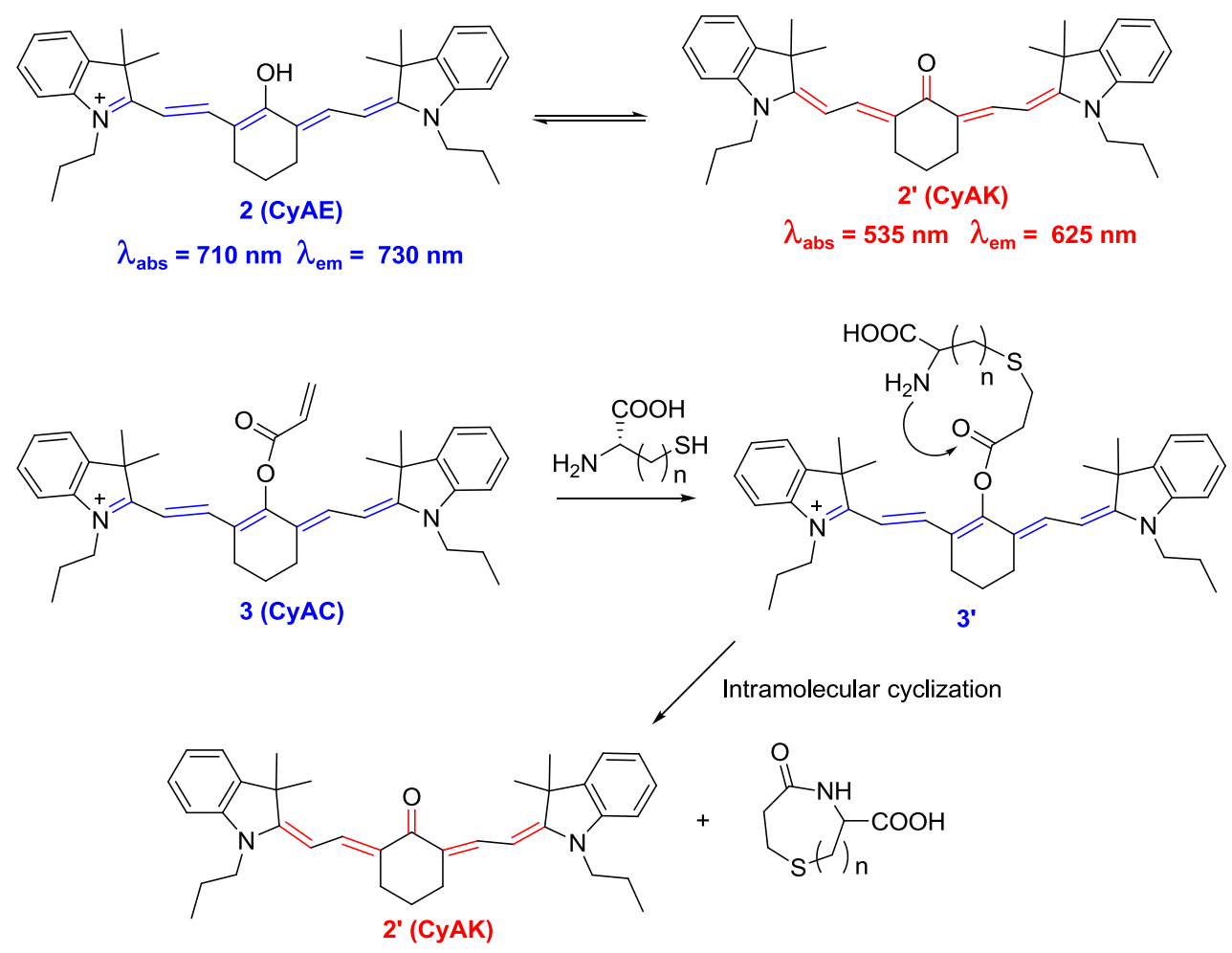

Figure 2. Comparison between CyAE (2) and CyAK (2') and reaction scheme for Cys selective probe $\mathbf{3}$ (CyAC).

On the other hand, new pyrene-based fluorescence probes, 4 (P-Hcy-1) and 5 (P-Hcy-2), were reported as Hcy selective probes by our group (Figure 3) [25]. P-Hcy-1 and P-Hcy-2 displayed selective fluorescence enhancements at $450 \mathrm{~nm}$ with Hcy in HEPES containing 10\% DMSO (0.01 M, pH 7.4). In both cases, the thiazinane heterocyclic ring formation of the aldehyde group turned out to be the reason for their Hcy selective fluorescence responses. The detection limits of P-Hcy-1 and P-Hcy-2 were calculated as $1.94 \times 10^{-6} \mathrm{M}$ and $1.44 \times 10^{-7} \mathrm{M}$, respectively. These Hcy probes were successfully applied to detect Hcy selectively in mammalian cells. 
Among the various approaches to design biothiol selective probes, fluorescence enhancement of $\mathrm{Cu}^{2+}$ complexes has been utilized for biothiol imaging. A new bis-pyrene derivative $\mathbf{6}$ was synthesized and a large fluorescence quenching effect was observed with $\mathrm{Cu}^{2+}$ at $\mathrm{pH} 7.4$ among the various metal ions (Figure 3) [26]. The addition of biothiols successfully revived the fluorescence of the 6-Cu${ }^{2+}$ ensemble, which was attributed to the displacement of the ligand to the biothiols for $\mathrm{Cu}^{2+}$. The addition of GSH, Cys or Hcy effectively induced fluorescence enhancement at $450 \mathrm{~nm}$. The detection limit of this $6-\mathrm{Cu}^{2+}$ ensemble for GSH was reported to be $0.16 \mu \mathrm{M}$. The $\mathrm{Cu}^{2+}$ ensemble could successfully image endogenous GSH in live cells and with the aid of two-photon microscopy (TPM), the 6- $\mathrm{Cu}^{2+}$ ensemble could also image GSH in living tissues.

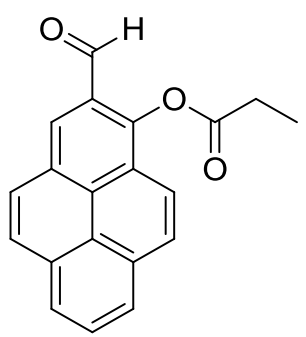

4 (P-Hcy-1)

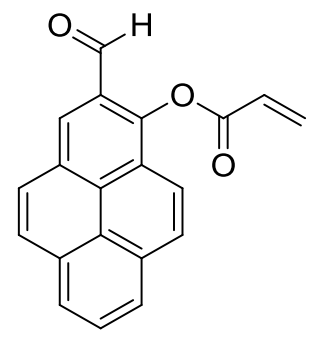

5 (P-Hcy-2)

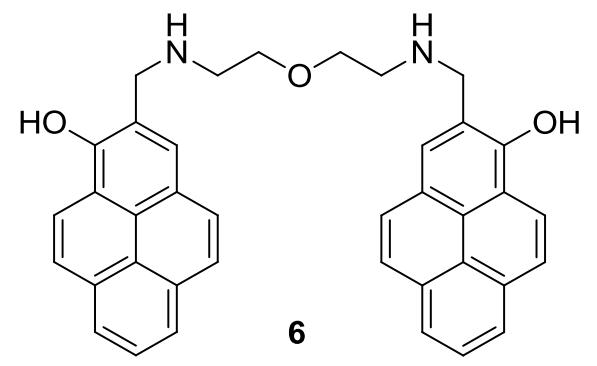

Figure 3. Structures of biothiol probes 4-6.

Compared to Cys and Hcy selective probes, GSH selective fluorescent imaging probes are still relatively rare. Recently, a new approach to designing GSH selective probes was reported by our group. We synthesized two cyanine derivatives containing a 2,4-dinitrobenzene sulfonamide group (7) and a 5-dimethylaminonaphthyl sulfonamide group (8), respectively, as NIR probes for biothiols (Figure 4) [27]. Probe 7 showed large fluorescence enhancements at $736 \mathrm{~nm}$ with GSH, Cys and Hcy in HEPES buffer (10 mM, pH = 7.4) containing 10\% DMSO. On the contrary, probe 8 displayed selective turn-on fluorescence with GSH. After reaction with biothiols, product $\mathbf{9}$ was confirmed by NMR and mass spectroscopy. These fluorescence changes with biothiols were further confirmed in HeLa cells. Probe $\mathbf{8}$ could image the GSH present in HeLa cells and no fluorescence was observed upon treatment with the thiol blocking agent, $N$-methylmaleimide (NMM). We also demonstrated that probe 9 can be used to monitor the intracellular levels of GSH modulated by $\mathrm{H}_{2} \mathrm{O}_{2}$ or lipopolysaccharide (LPS) treatment. NIR probe 8 was further applied to monitor GSH in a mouse model (Figure 5), especially in liver, kidney, lung, and spleen tissues. It is reported that overdose of the painkiller, acetaminophen, can cause severe liver damage and a depletion of GSH in liver and kidney cells. The depletion of GSH in mouse tissue cells was successfully monitored using probe $\mathbf{8}$.

For Cys and Hcy selective probes, we developed the aryl-thioether substituted nitrobenzothiadiazole 10 (Figure 6) [28]. Only Cys and Hcy induced fluorescence enhancement $\left(\lambda_{\max }=535 \mathrm{~nm}\right.$ ) at pH 7.4. The proposed reaction scheme with Cys and Hcy is illustrated in Figure 6. We also reported that probe 10 could image these biothiol species in live cells. It is known that the nucleophilicity of Cys $\left(p K_{a}\right.$ 8.53 ) is better than that of Hcy ( $\left.p K_{a} 10.00\right)$. In addition, we expect that the $p$-amino group in probe $\mathbf{1 0}$ can manipulate the aryl substitution selectivity at lower $\mathrm{pH}$. Indeed, we observed nice selectivity for Cys over Hcy in a citric acid- $\mathrm{Na}_{2} \mathrm{HPO}_{4}(0.01 \mathrm{M}, \mathrm{pH}$ 6.0) solution containing $1 \%$ DMSO. 


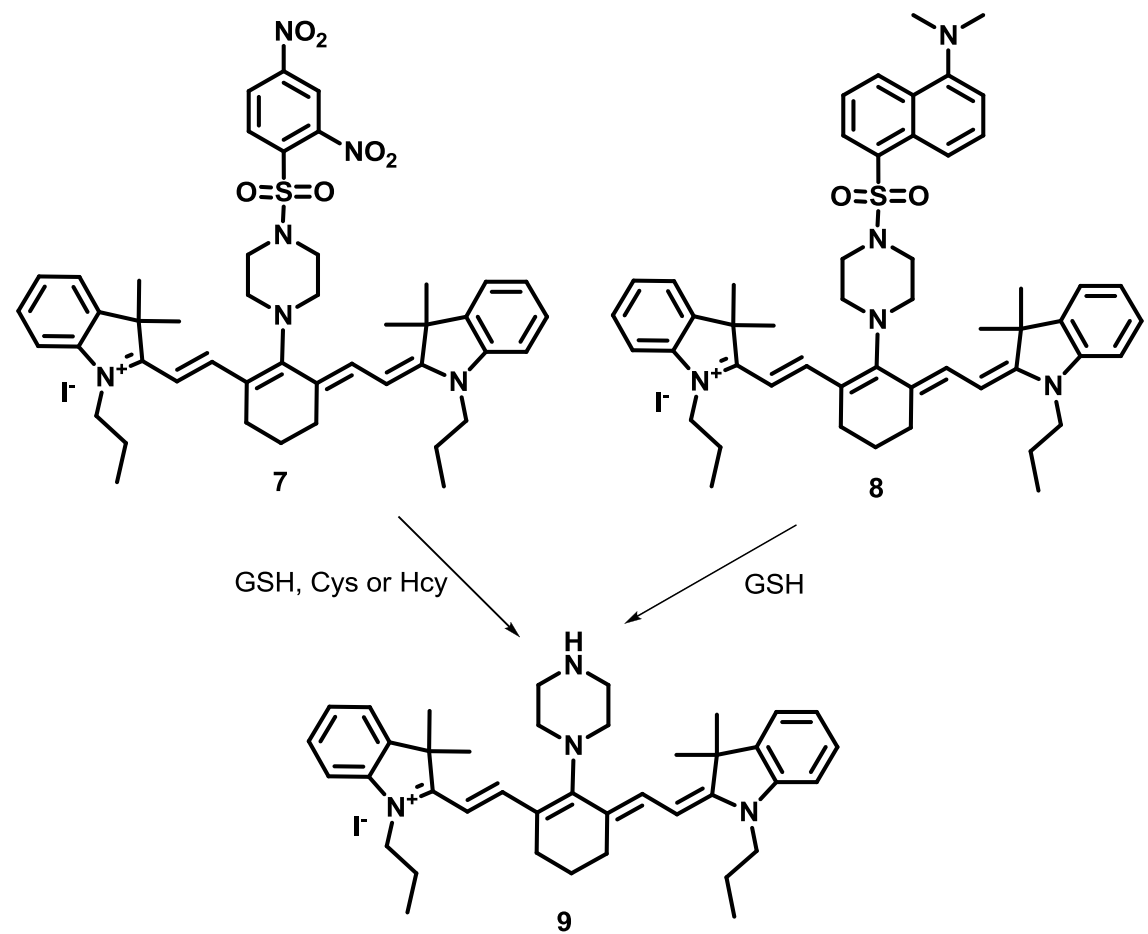

Figure 4. Reaction scheme for biothiol selective probe 7 and GSH selective probe 8 .
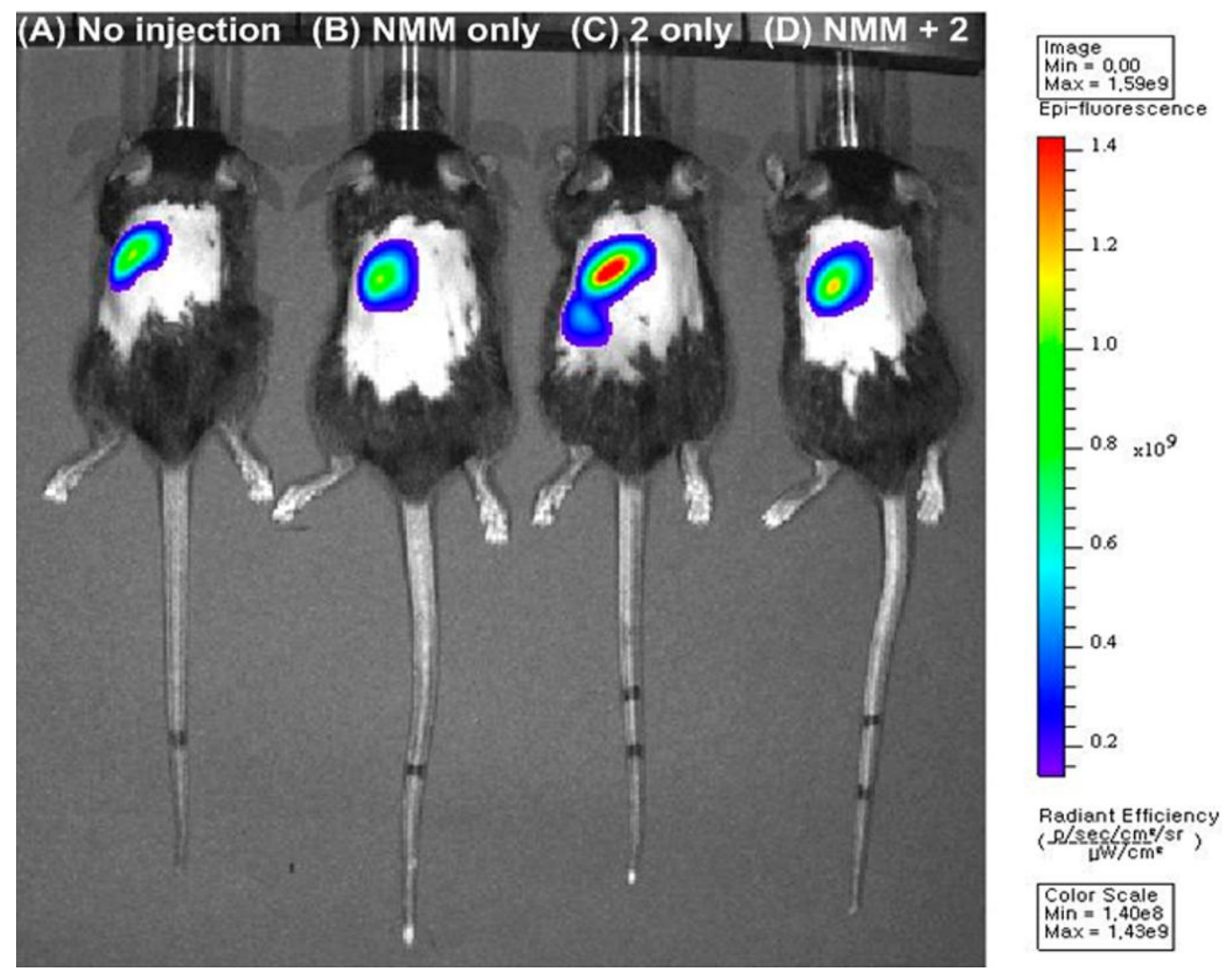

Figure 5. In vivo images of a mouse injected with probe $8(50 \mu \mathrm{M})$ or NMM $(20 \mathrm{mM})$ intravenously for $20 \mathrm{~min}$. Fluorescence images of: (A) the mouse not injected with probe $\mathbf{8}$ (No injection); (B) the mouse injected with NMM (NMM only); (C) the mouse injected with probe 8 (8 only); (D) the mouse injected with probe $\mathbf{8}$ after pre-injection with NMM. (Reprinted from reference [27]). 


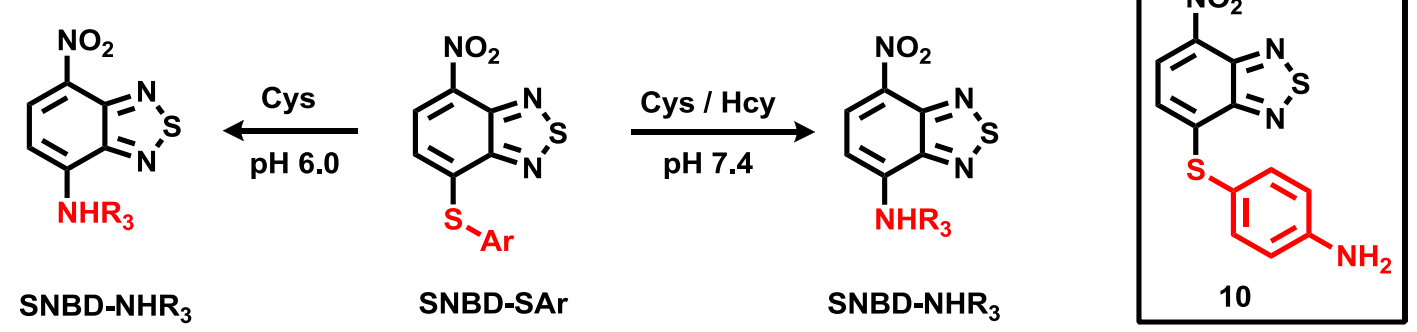

Figure 6. Structure of probe $\mathbf{1 0}$ and its reaction scheme with Cys and Hcy.

\subsection{Fluorescent Imaging Probes for Reactive Oxygen Species (ROS) and Reactive Nitrogen} Species (RNS)

Reactive oxygen species (ROS) and reactive nitrogen species (RNS) are active targets for fluorescent probes due to their significance in human health and disease [29]. We also contributed to the development of ROS and RNS selective fluorescent probes, especially for hypochlorous acid ( $\mathrm{HOCl}$ ), hydrogen peroxide $\left(\mathrm{H}_{2} \mathrm{O}_{2}\right)$ and peroxynitrite $\left(\mathrm{ONOO}^{-}\right)$.

Novel rhodamine derivatives 11-13 were synthesized as fluorescent probes for $\mathrm{HOCl}$ (Figure 7) [30]. Fluorescent increase upon the addition of $\mathrm{HOCl}$ was attributed to the ring-opening process through sulfur/selenium oxidation as shown in Figure 7. Probes $\mathbf{1 1}$ and $\mathbf{1 2}$ showed highly selective fluorescence enhancement with $\mathrm{HOCl}$ among the various ROS, such as $\mathrm{H}_{2} \mathrm{O}_{2}, \mathrm{NO} \cdot \bullet \cdot \mathrm{OH}, \mathrm{ROO} \cdot, \mathrm{ONOO}^{-},{ }^{1} \mathrm{O}_{2}$, and - $\mathrm{O}_{2}{ }^{-}$in $\mathrm{KH}_{2} \mathrm{PO}_{4}$ buffer ( $\mathrm{pH} 5.5,1 \% \mathrm{CH}_{3} \mathrm{CN}$ ). On the other hand, probe 13 displayed a lower selectivity for $\mathrm{HOCl}$, probably due to the higher susceptibility to selenolactone by oxidants. The detection limits of $\mathrm{HOCl}$ probes 11-13 were calculated as $0.4 \mu \mathrm{M}, 0.6 \mu \mathrm{M}$ and $2 \mu \mathrm{M}$, respectively. Furthermore, probe 11 could image bacteria-mediated microbicidal $\mathrm{HOCl}$ production in the mucosal epithelia in fruit fly.

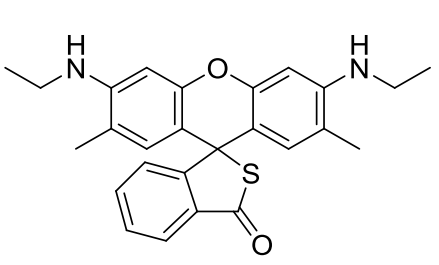

11

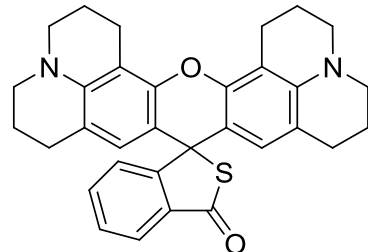

12

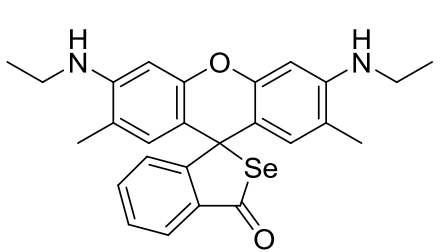

13

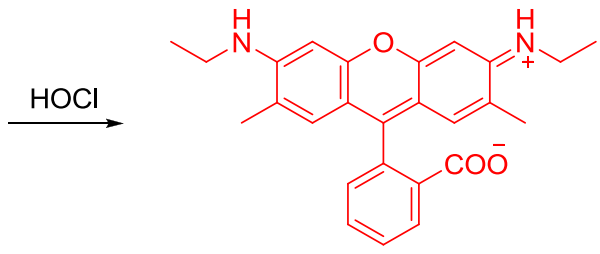

rhodamine 19

Figure 7. Structures of $\mathrm{HOCl}$ selective fluorescent probes 11-13 and reaction scheme for $\mathbf{1 1}$ with $\mathrm{HOCl}$.

We extended this design concept to the so-called "dual-lock" fluorescent probe 14 (FBS) for HOCl (Figure 8) [31], in which two reacting groups, such as aryl boronate and thiolactone, are introduced. 
Among the various $\mathrm{ROS}, \mathrm{H}_{2} \mathrm{O}_{2}$ and $\mathrm{ONOO}^{-}$could convert arylboronates to phenol to yield $\mathbf{1 4}^{\prime}$, which is still non-fluorescent. On the contrary, only $\mathrm{HOCl}$ can react with both arylboronates and thiolactone to give fluorescein (14") resulting in green fluorescence. Another advantage of FBS would be its large $\mathrm{pH}$ window between $\mathrm{pH} 5.5$ and $\mathrm{pH}$ 9.3. FBS was further applied to detect physiological HOCl production in vivo. For this purpose, we chose the drosophila gut system, a well-known HOCl producing organ. FBS could successfully image bacterial-induced $\mathrm{HOCl}$ production in situ when bacterial extracts were administered to the flies via oral ingestion.

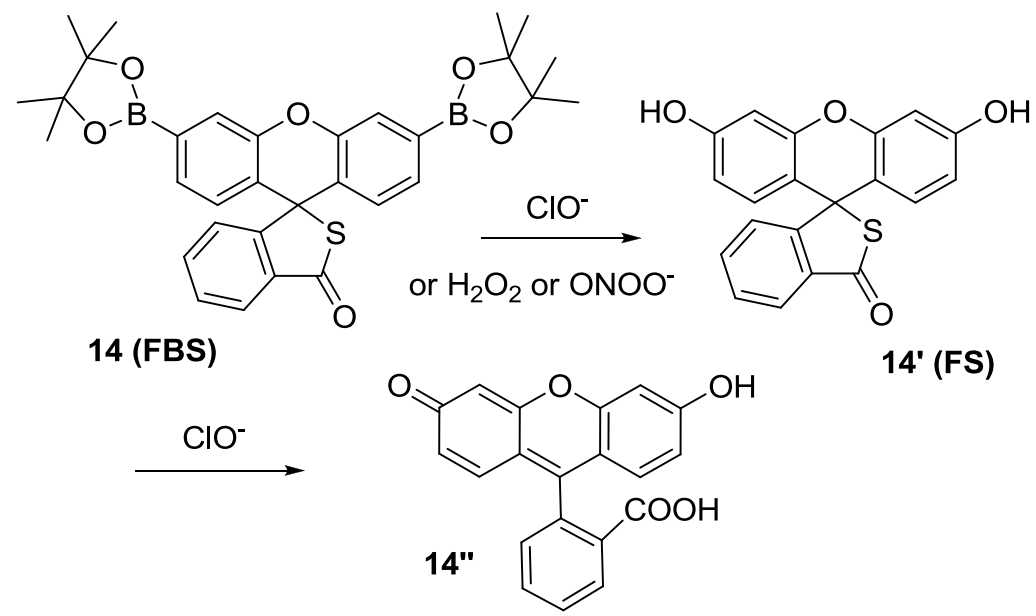

Figure 8. Reaction scheme for $\mathrm{HOCl}$ selective fluorescent probe 14 (FBS).

Recently, the imidazoline-2-thione containing $\mathrm{OCl}^{-}$probes, 15 (PIS) and 16 (NIS), were designed as new fluorescent probes for $\mathrm{HOCl}$ (Figure 9) [32]. Upon the addition of up to $5 \mu \mathrm{M} \mathrm{OCl}^{-}$, a new absorbance peak for PIS at $378 \mathrm{~nm}$ appeared with the sacrifice of the peak at $420 \mathrm{~nm}$ in PBS (pH 7.4). Addition of $\mathrm{OCl}^{-}(0-10 \mu \mathrm{M})$ also induced a new fluorescence emissionat $505 \mathrm{~nm}$. We believe the PIS reaction with $\mathrm{HOCl}$ generates imidazolium salt $\mathbf{1 7}$ and the proposed mechanism is illustrated in Figure 9. NIS displayed similar changes with shorter emission wavelengths. To demostrate the possible bio-applications of these probes, PIS was used to visualize $\mathrm{OCl}^{-}$generation in RAW 264.7 macrophages, which were activated by lipopolysaccharides (LPS) and then IFN- $\gamma \cdot \mathrm{H}_{2} \mathrm{O}_{2}$ produced by phorbol myristate acetate (PMA) was transformed to $\mathrm{OCl}^{-}$by MPO. As expected, bright green fluorescence was observed in RAW 264.7 macrophages. When the known MPO inhibitors, 4-aminobenzoicacid hydrazide (ABAH) and flufenamic acid (FFA) were added, distinct fluorescence quenching was observed, which means that PIS successfully visualized $\mathrm{OCl}^{-}$production in RAW 264.7 macrophages. We designed a co-culture system of RAW 264.7 macrophages and HeLa cell. When these cell mixtures were treated with stimulants to generate $\mathrm{OCl}^{-}$, the macrophages and HeLa cells had distinguishably different shapes and further, green fluorescence was observed only for RAW 264.7 macrophages. Finally, PIS was utilized to detect $\mathrm{OCl}^{-}$by using TPM. As shown in Figure 10, under similar conditions of RAW 264.7 macrophage experiments, PIS could successfully image $\mathrm{OCl}^{-}$production. 
<smiles>Cn1c(=S)n(C)c2cc3nc4ccccc4nc3cc21</smiles>

15 (PIS)<smiles>Cn1c(=S)n(C)c2cc3ccccc3cc21</smiles>

16 (NIS)<smiles>Cc1ccc2nc3cc4c(cc3nc2c1)n(C)c(SO)[n+]4C</smiles>

$15^{\prime}$<smiles></smiles>

Figure 9. Structures of 15 (PIS) and 16 (NIS) and reaction scheme of 15 (PIS) with HOCl.
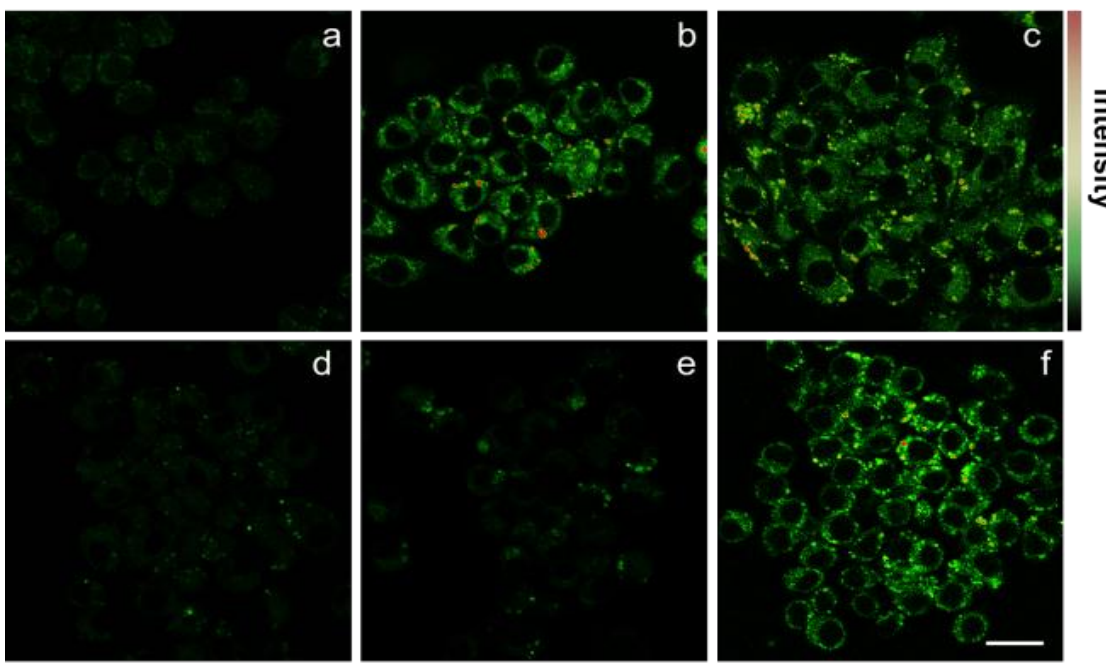

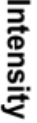
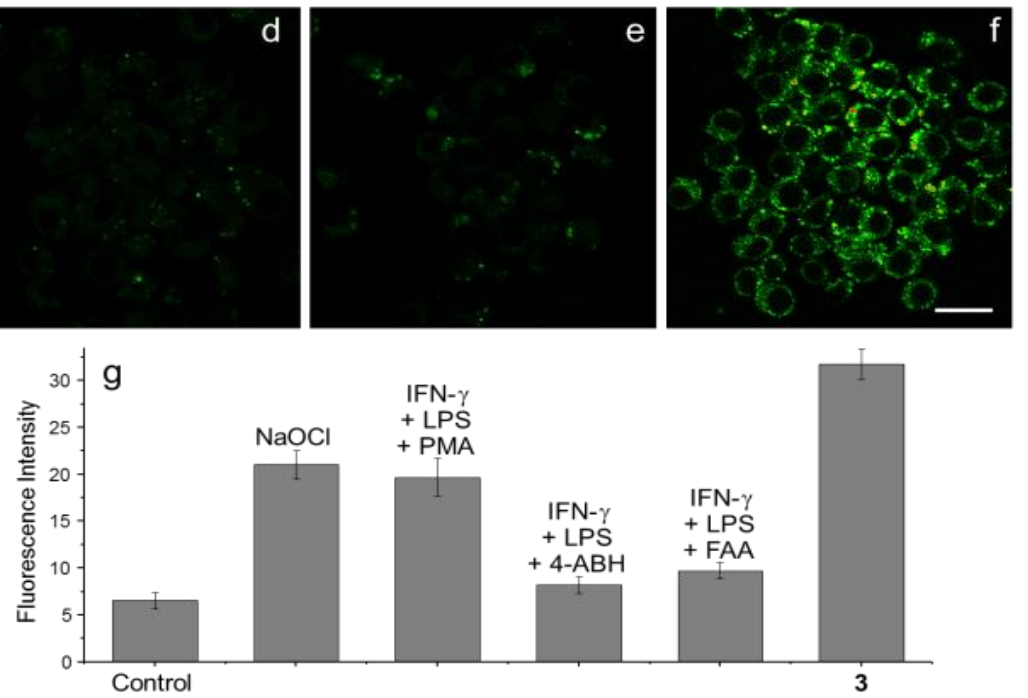

Figure 10. TPM images of (a-e) PIS and (f) $16(10 \mu \mathrm{M}, \rho \mathrm{DMF}=0.5 \%)$ labeled RAW 264.7 cells. (a) Control image; (b) Cells pretreated with $\mathrm{NaOCl}(200 \mu \mathrm{M})$ for $30 \mathrm{~min}$ and then incubated with PIS; (c) Cells pretreated with LPS (100 ng/mL) for $16 \mathrm{~h}$, IFN- $\gamma$ (400 U/mL) for $4 \mathrm{~h}$, and PMA (10 nM) for $30 \mathrm{~min}$ and then with PIS; (d) Cells pretreated with LPS, IFN- $\gamma$, and 4-ABAH $(50 \mu \mathrm{M})$ for $4 \mathrm{~h}$ and then incubated with PIS; (e) Cells pretreated with LPS, IFN- $\gamma$, and FAA $(50 \mu \mathrm{M})$ for $4 \mathrm{~h}$ and then with PIS; (g) Average TPEF intensities in (a-f), $n=5$. Scale bar: $20 \mu \mathrm{m}$. (Reprinted from reference [32]). 
James and our group recently reported a unique system for sensing peroxynitrite $\left(\mathrm{ONOO}^{-}\right)$using boronate-based fluorescent probe 17 and D-fructose (Figure 11) [33]. When D-fructose was added to probe $\mathbf{1 7}$ at $\mathrm{pH}$ 7.3, a large fluorescence enhancement was observed. Among the various ROS and RNS species, only $\mathrm{ONOO}^{-}$induced a significant fluorescence quenching effect. We believe that the unique interaction of probe 17 with D-fructose plays two important roles in this study, namely to strengthen the fluorescence signal and to prevent the oxidation of boronic acid by other ROS/RNS. This system was also successfully applied to image endogenous and exogenous $\mathrm{ONOO}^{-}$in RAW 264.7 cells and HeLa cells.
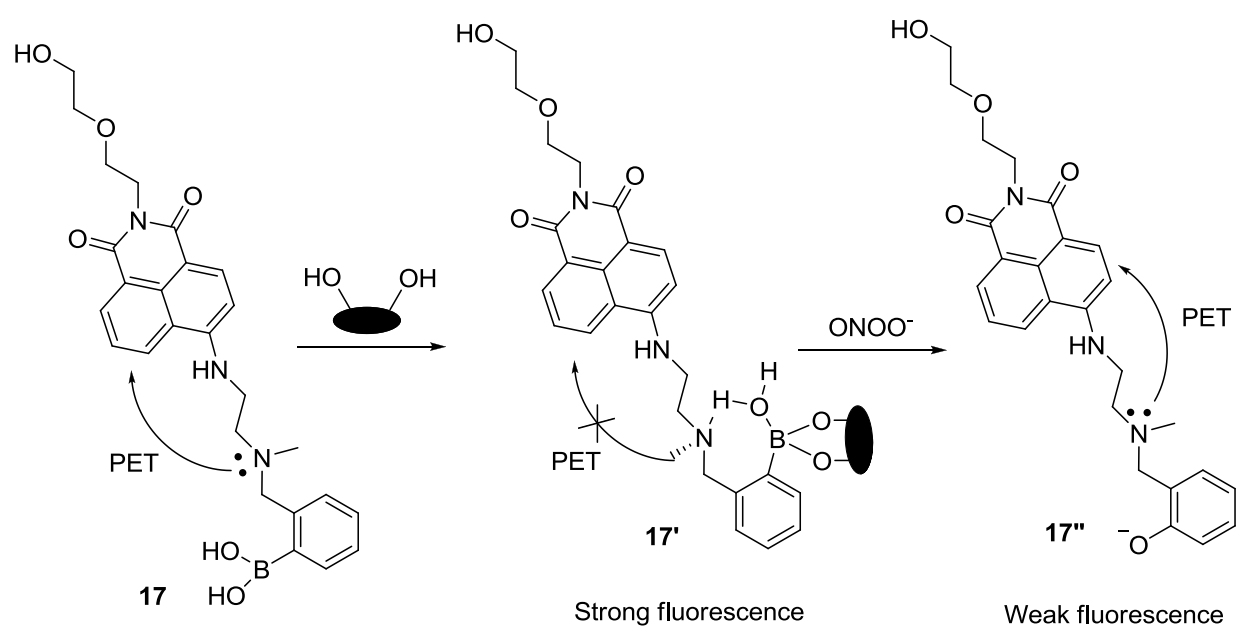

Figure 11. Reaction scheme for probe 17 with $\mathrm{ONOO}^{-}$.

The red emitting probe 18 (CHCN) composed of a linked coumarin-hemicyanine was recently developed as a dual ratiometric and colorimetric probe for peroxynitrite $\left(\mathrm{ONOO}^{-}\right)$(Figure 12) [34]. Among the various ROS and RNS, only $\mathrm{ONOO}^{-}$induced significant ratiometric fluorescence changes $\left(\mathrm{F}_{515 \mathrm{~nm}} / \mathrm{F}_{635 \mathrm{~nm}}\right)$. The proposed reaction mechanism is shown in Figure 12. The formation of two products, 1,3,3-trimethyloxindole and Coum-CHO was also confirmed. As shown in Figure 13, 18 (CHCN) displayed ratiometric fluorescence changes for exogenous and endogenous $\mathrm{ONOO}^{-}$during the phagocytic immune response. More specifically, red fluorescence was reduced with the enhancement of green fluorescence when RAW 264.7 cells were treated with LPS and IFN-g followed by additional stimulation with PMA. Treatment with a superoxide scavenger, 2,2,6,6-tetramethyl-1-piperidinyloxy (TEMPO) or an NO synthase inhibitor, aminoguanidine, caused no changes in the ratios of $\mathrm{red} /$ green fluorescence.

Recently, a new boronate-based naphthalimide derivative 19 was developed as a $\mathrm{H}_{2} \mathrm{O}_{2}$ selective fluorescent probe (Figure 14) [35]. Figure 14 explains the design strategy for probe 19, in which a morpholine moiety acts as a lysosome-targetable group and a p-dihydroxyborylbenzyloxycarbonyl group was used as a transponder. Among various ROS and RNS, probe 19 showed a selective fluorescent enhancement at $528 \mathrm{~nm}$ at pH 7.4 (0.1 M PBS containing 1\% DMF). Probe 19 was clearly localized in the lysosomes, which was confirmed by costaining with LysoTracker Blue DND-22. Probe 19 was further applied to image the level of endogenous and exogenous $\mathrm{H}_{2} \mathrm{O}_{2}$ in the lysosome of the RAW 264.7 cells. Furthermore, time-dependent fluorescence of $\mathbf{1 9}$ in the cells was reported. 

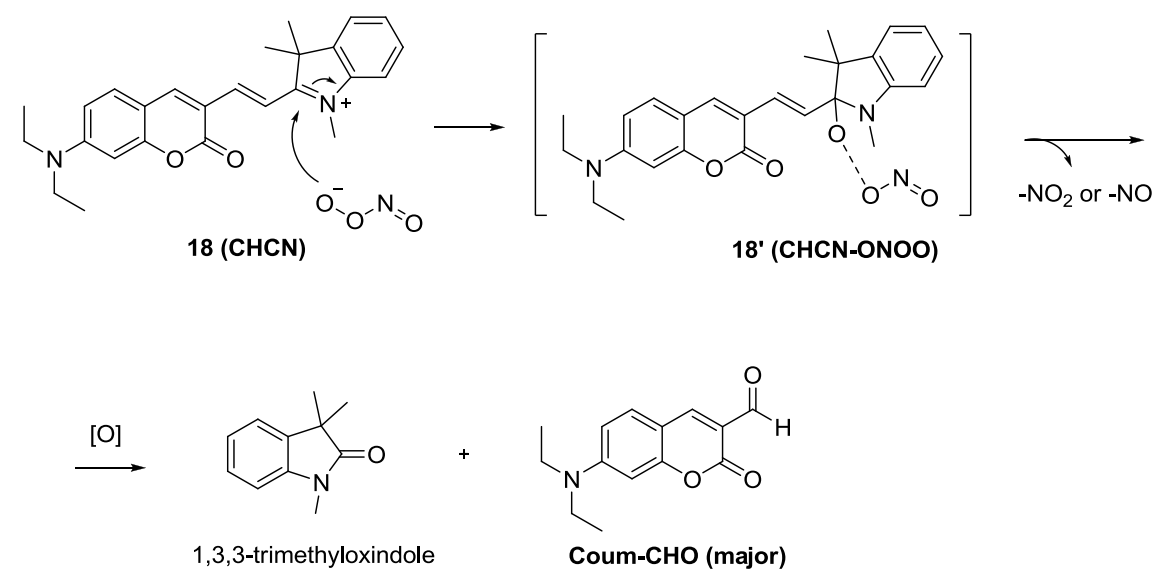

Figure 12. Reaction scheme of peroxinitrite probe $\mathbf{1 8 .}$
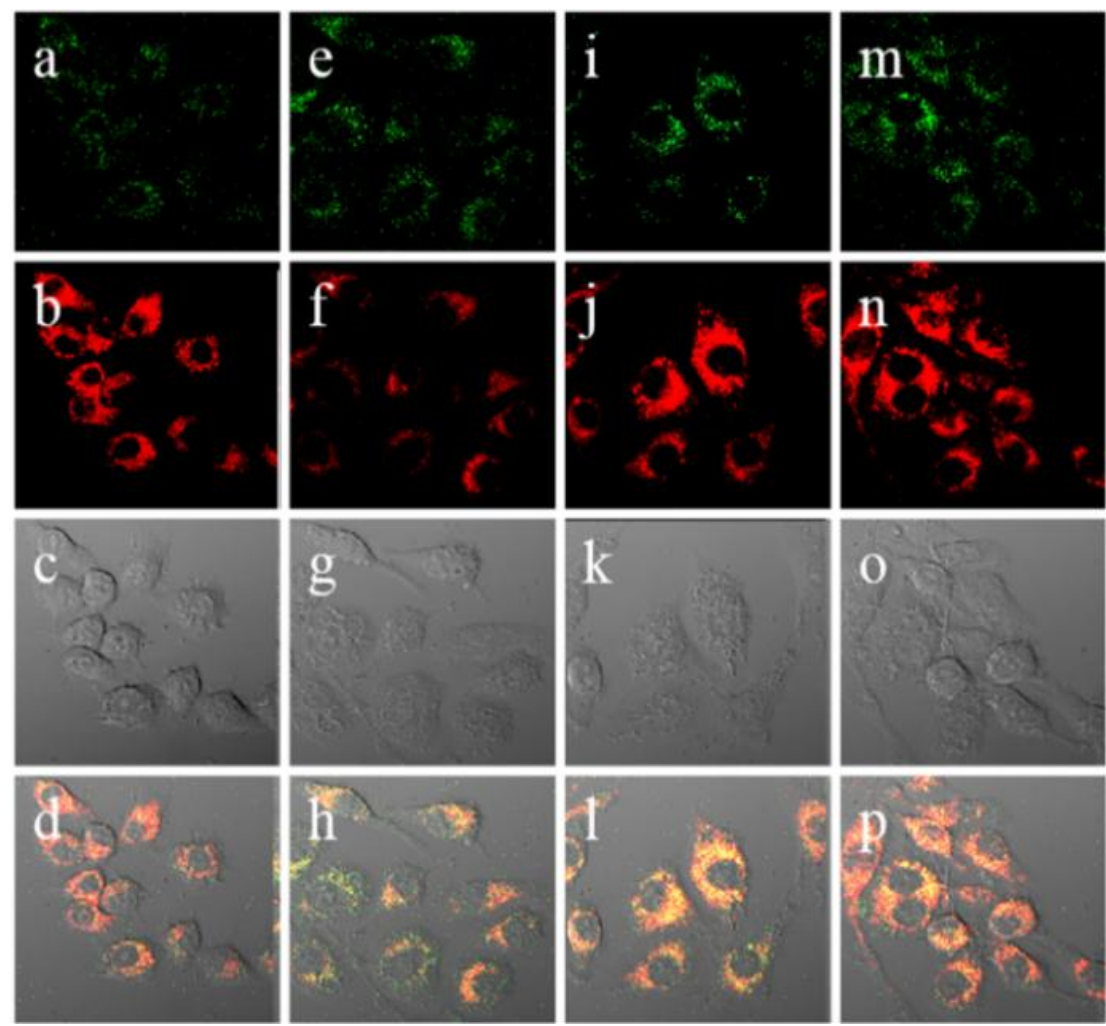

Figure 13. Confocal ratiometric fluorescence images of RAW 264.7 cells for endogenous $\mathrm{ONOO}^{-}$during phagocytic immune response. The cells were stained with $5 \mu \mathrm{M} 18$ (CHCN) for $30 \mathrm{~min}$ and then washed with DPBS before imaging. (a) Control; (e) lipopolysaccharides (LPS) $(1 \mu \mathrm{g} / \mathrm{mL})$ for $16 \mathrm{~h}$, interferon- $\gamma(50 \mathrm{ng} / \mathrm{mL})$ for $4 \mathrm{~h}$, PMA (10 $\mathrm{nM})$ for $30 \mathrm{~min}$; (i) LPS $(1 \mu \mathrm{g} / \mathrm{mL})$ for $16 \mathrm{~h}$, interferon- $\gamma(50 \mathrm{ng} / \mathrm{mL})$ for $4 \mathrm{~h}$, PMA $(10 \mathrm{nM})$ for $30 \mathrm{~min}$, and then AG $(1 \mathrm{mM})$ for $16 \mathrm{~h}$; (m) LPS $(1 \mu \mathrm{g} / \mathrm{mL})$ or $16 \mathrm{~h}$, interferon- $\gamma(50 \mathrm{ng} / \mathrm{mL})$ for $4 \mathrm{~h}$, PMA $(10 \mathrm{nM})$ for $30 \mathrm{~min}$, and then TEMPO $(100 \mu \mathrm{M})$ for $16 \mathrm{~h}$. The green channel $(\mathbf{a}, \mathbf{e}, \mathbf{I}, \mathbf{m})$ represents the fluorescence obtained at 490-540 nm with an excitation wavelength at $473 \mathrm{~nm}$, the red channel $(\mathbf{b}, \mathbf{f}, \mathbf{j}, \mathbf{n})$ represents the fluorescence obtained at $575-675 \mathrm{~nm}$ with an excitation wavelength at $559 \mathrm{~nm}$, images $(\mathbf{c}, \mathbf{g}, \mathbf{k}, \mathbf{o})$ represent DIC channels (differential interference contrast), and images $(\mathbf{d}, \mathbf{h}, \mathbf{I}, \mathbf{p})$ represent merged images of red and green channels, respectively. (Reprinted from reference [34]). 


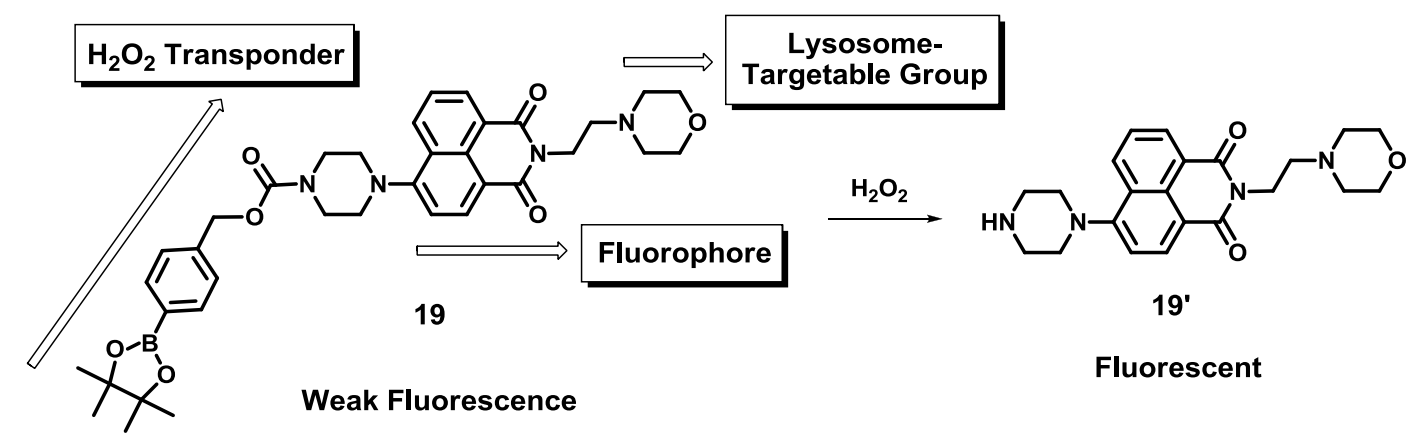

Figure 14. Design strategy of $\mathrm{H}_{2} \mathrm{O}_{2}$ selective probe 19 and its reaction scheme with $\mathrm{H}_{2} \mathrm{O}_{2}$.

\subsection{Fluorescent Imaging Probes for Metal Ions}

Among the biologically abundant metal ions, $\mathrm{Zn}^{2+}$ is known to play key roles in a variety of physiological processes, such as Alzheimer's disease, epilepsy, ischemic stroke, etc. Due to the lower reactivity of this metal ion, most $\mathrm{Zn}^{2+}$ selective fluorescent probes are based on the design of selective ligands and effective fluorescence changes [36].

In 2009, we reported a 7-nitrobenz-2-oxa-1,3-diazole (NBD) derivative as a fluorescent and colorimetric probe for $\mathrm{Zn}^{2+}$ (Figure 15) [37]. Among the various metal ions, probe 20 displayed a selective fluorescence enhancement only with $\mathrm{Zn}^{2+}$ in $100 \%$ aqueous solution (0.1 M HEPES, pH 7.2). In addition, red to yellow color change with $\mathrm{Zn}^{2+}$ was observed by the naked eye. A large fluorescence enhancement as well as colorimetric changes was attributed to photoinduced electron transfer (PET) and internal charge transfer (ICT) mechanisms as shown in Figure 15. The dissociation constant $\left(K_{\mathrm{d}}\right)$ for $\mathbf{2 0}$ was reported as $1.3 \mu \mathrm{M}$. Relatively high concentrations of $\mathrm{Zn}^{2+}$ are present in pancreatic islets, which are known to play a key role in insulin biosynthesis and storage. The practical-use probe $\mathbf{2 0}$ could successfully detect the intrinsic $\mathrm{Zn}^{2+}$ Ions in pancreatic $\beta$-cells.

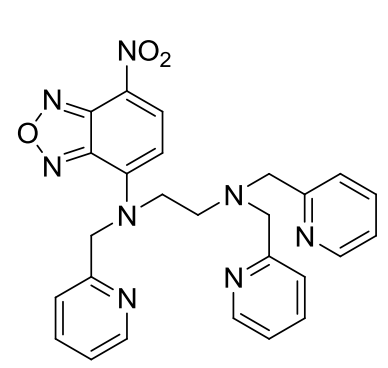

20

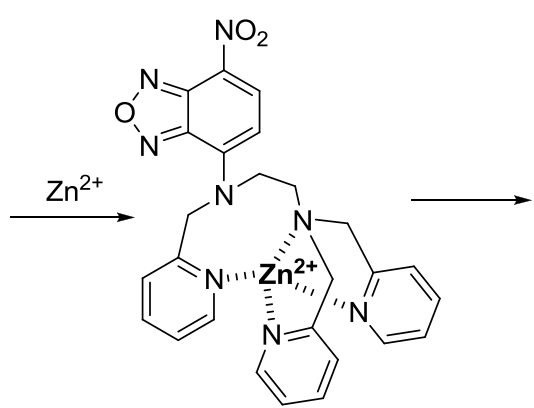

PET blocked

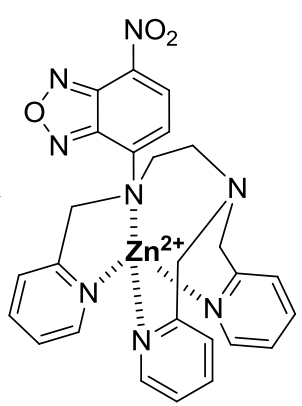

ICT

Figure 15. Proposed binding mode of probe 20 with $\mathrm{Zn}^{2+}$.

We recently proposed a new strategy called "receptor transformer" [38]. As shown in Figure 16, the naphthalimide derivative (21) binds $\mathrm{Zn}^{2+}$ in an imidic acid tautomeric form of the probe in aqueous solutions while other heavy transition metal ions, especially $\mathrm{Cd}^{2+}$, bind to probe $\mathbf{2 1}$ in an amide tautomeric form. With the aid of these unique binding modes, probe $\mathbf{2 1}$ displayed a selective fluorescence enhancement for $\mathrm{Zn}^{2+}$ over other metal ions with a red-shift from 483 to $514 \mathrm{~nm}$. On the other hand, the addition of $\mathrm{Cd}^{2+}$ induced an enhanced blue-shift in emission from 483 to $446 \mathrm{~nm}$ in aqueous solution, 
which binds to probe 21 with an amide tautomeric form. Therefore, green and blue fluorescence was observed for in vitro and in vivo $\mathrm{Zn}^{2+}$ and $\mathrm{Cd}^{2+}$, respectively. These different binding modes were confirmed by NMR and IR data. The dissociation constants $\left(K_{\mathrm{d}}\right)$ for $\mathrm{Zn}^{2+}$ and $\mathrm{Cd}^{2+}$ were reported as $5.7 \mathrm{nM}$ and $48.5 \mathrm{nM}$, respectively. Finally, as shown in Figure 17, 21 could successfully detect intrinsic zinc ions during the development of living zebrafish embryos.

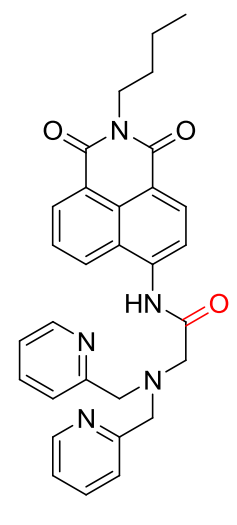

21

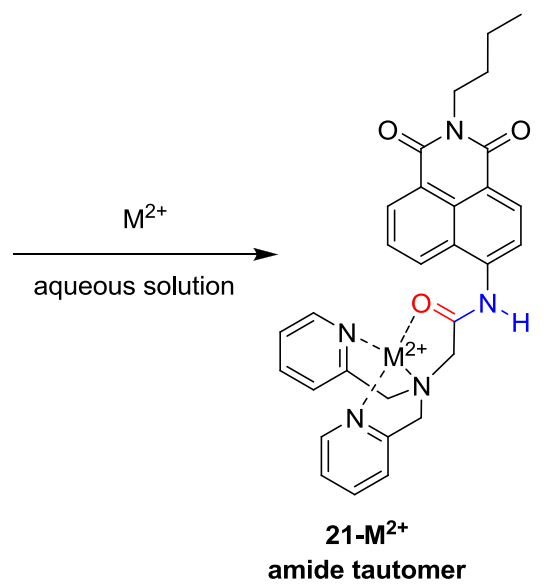

amide tautomer

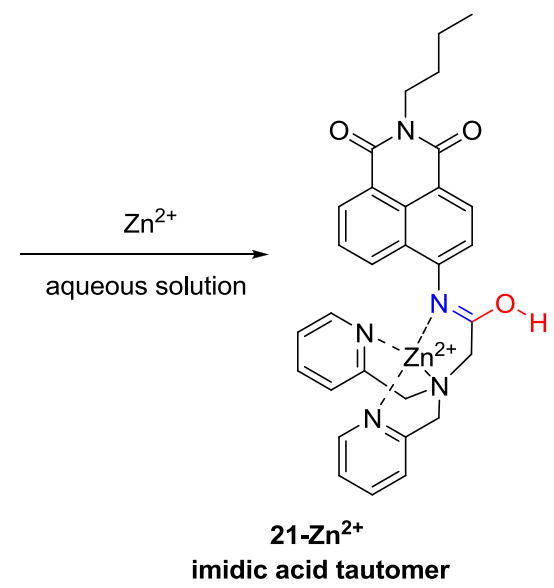

imidic acid tautomer

Figure 16. Proposed binding modes of probe 21 with metal ions.
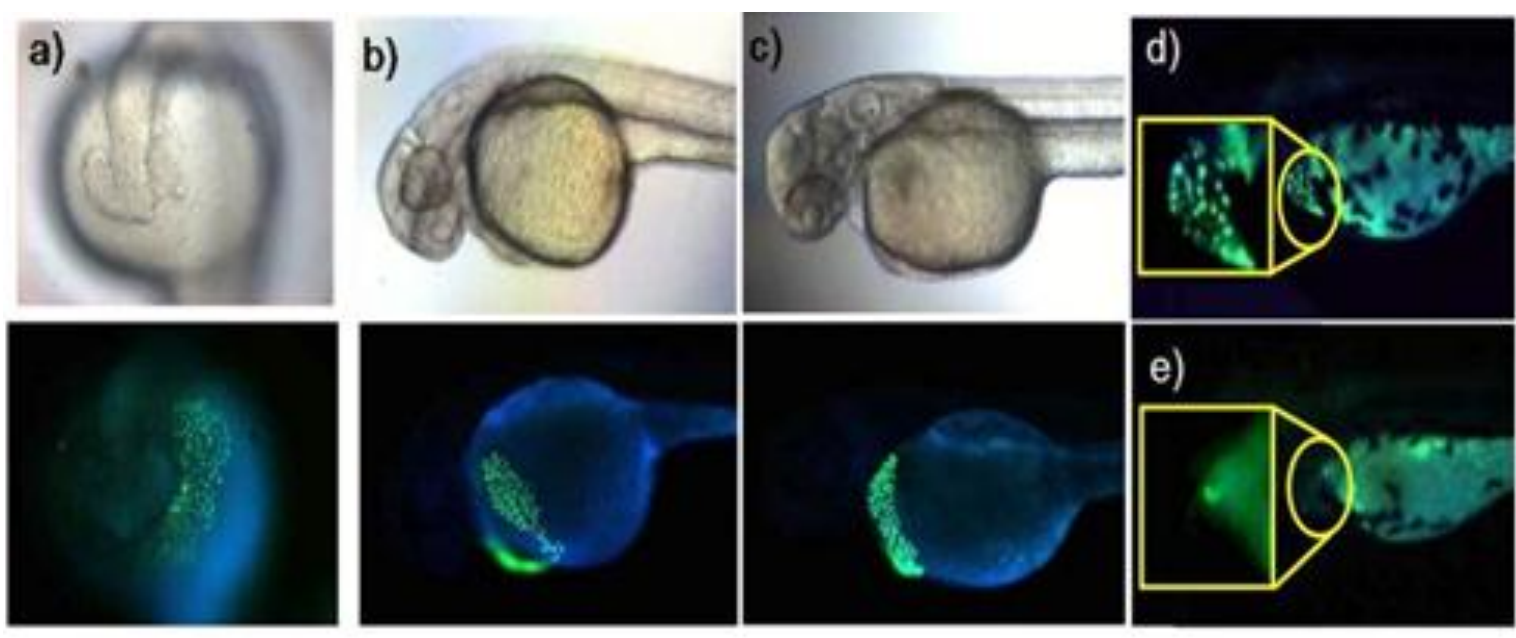

Figure 17. Zebrafish incubated with probe $21(5 \mu \mathrm{M})$. (a) Images of 19 h-old; (b) 36 h-old; and (c) 48 h-old zebrafish incubated with 21 for 1 h; (d) Image of 54 h-old zebrafish incubated with 21 for $1 \mathrm{~h}$ and (e) image of 54 h-old zebrafish after initial incubation with $100 \mu \mathrm{M}$ TPEN for $1 \mathrm{~h}$ and subsequent treatment of washed zebrafish with 21 for $1 \mathrm{~h}$. (Reprinted from reference [38]).

A new cyanine-based NIR fluorescent probe 22 bearing tris(2-pyridylmethyl)amine (TMPA) was reported by our group to detect endogenous zinc ions in living cells and organisms (Figure 18) [39,40]. The unique hypsochromic shifts with $\mathrm{Zn}^{2+}$ in absorption (670-510 nm) and emission (730-590 nm) were explained as follows: Introduction of $\mathrm{Zn}^{2+}$ to the TMPA moiety in $\mathbf{2 2}$ deprotonated the amine attached to the center of the polymethine chain of tricarbocyanine to form an imine, which induced the less delocalized diamino-tetraene group. Probe 22 displayed a very strong binding affinity $\left(K_{\mathrm{d}}=1.2 \mathrm{nM}\right)$, which means that probe 22 can serve as an excellent probe to monitor $\mathrm{Zn}^{2+}$ in the nanomolar range. Most 
importantly, probe 22 was used to detect $\mathrm{Zn}^{2+}$ released during apoptosis induced by the addition of $\mathrm{H}_{2} \mathrm{O}_{2}$. It is known that metallothioneins, expressed in neuromasts, play a key role in $\mathrm{Zn}^{2+}$ homeostasis [41]. Figure 19 clearly shows that probe 22 could detect intact $\mathrm{Zn}^{2+}$ in the neuromasts of zebrafish.
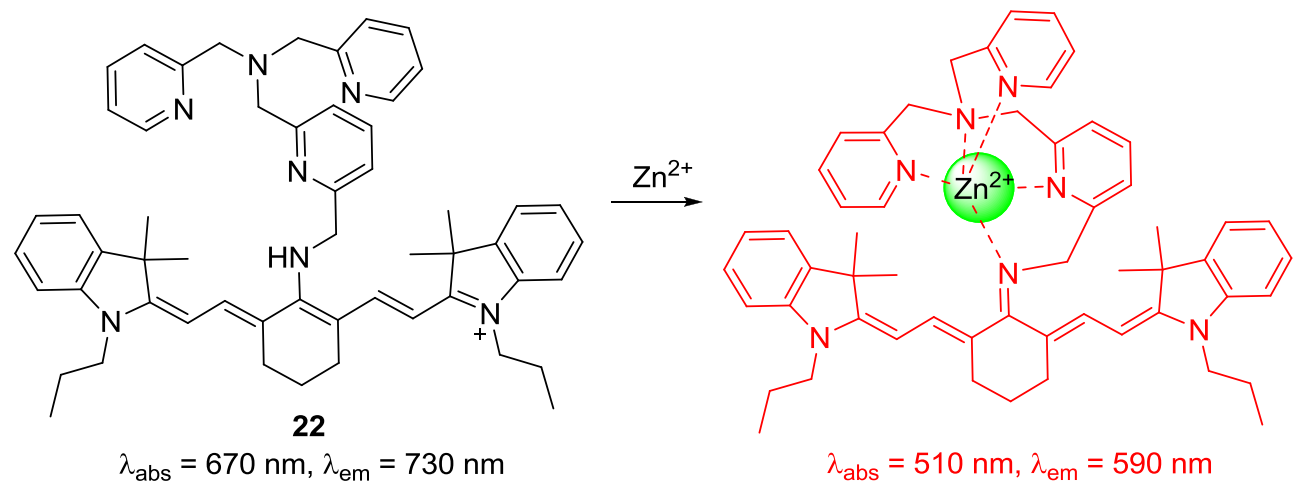

Figure 18. Proposed binding mode of probe 22 with $\mathrm{Zn}^{2+}$.
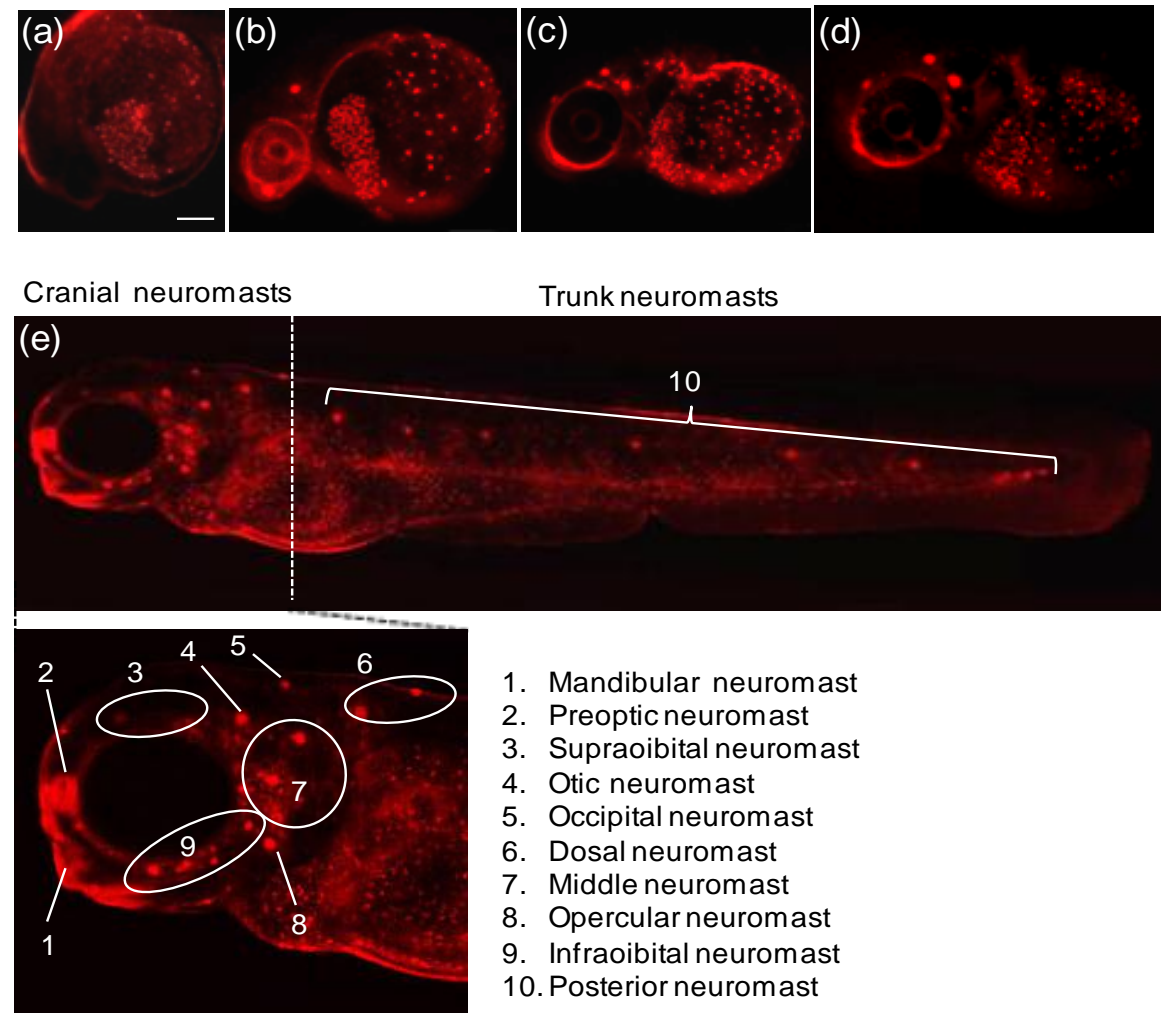
1. Mandibular neuromast
2. Preoptic neuromast
3. Supraoibital neuromast
4. Otic neuromast
5. Occipital neuromast
6. Dosal neuromast
7. Middle neuromast
8. Opercular neuromast
9. Infraoibital neuromast
10. Posterior neuromast

Figure 19. Fluorescent detection of intact zinc ions in zebra fish using probe 22 (a) $24 \mathrm{~h}$; (b) $36 \mathrm{~h}$; (c) $48 \mathrm{~h}$; (d) $72 \mathrm{~h}$ and (e) $96 \mathrm{~h}$-old zebra fish incubated with probe 22 for $1 \mathrm{~h}$. (Reprinted from reference [39]).

Due to the high toxicity of mercury and methyl mercury, the development of new fluorescent probes has been actively explored by many groups [42]. During the last few years, our group has utilized the unique ring-opening process of spirolactam in rhodamine derivatives to develop fluorescent and colorimetric probes for various metal ions in which the ring-opening process of spirolactam can induce large fluorescent enhancements and colorimetric changes (colorless to red) [43,44]. 
Two simple rhodamine hydrazone derivatives bearing thiol (23) and carboxylic acid (24) groups were developed as selective fluorescent and colorimetric probes for $\mathrm{Hg}^{2+}$ (Figure 20) [45]. Upon the addition of $\mathrm{Hg}^{2+}$, the selective ring-opening process of spirolactams in probes $\mathbf{2 3}$ and $\mathbf{2 4}$ were observed in $\mathrm{CH}_{3} \mathrm{CN}-\mathrm{H}_{2} \mathrm{O}(1: 99, v / v)$ solution, which was accompanied by large fluorescent enhancement and colorimetric change. The detection limits were calculated as $1 \mathrm{nM}$ for $\mathbf{2 3}$ and $4.2 \mathrm{nM}$ for $\mathbf{2 4}$. Both probes could successfully image $\mathrm{Hg}^{2+}$ accumulated in the nematode $C$. elegans, which was pretreated with nanomolar concentrations of $\mathrm{Hg}^{2+}$.
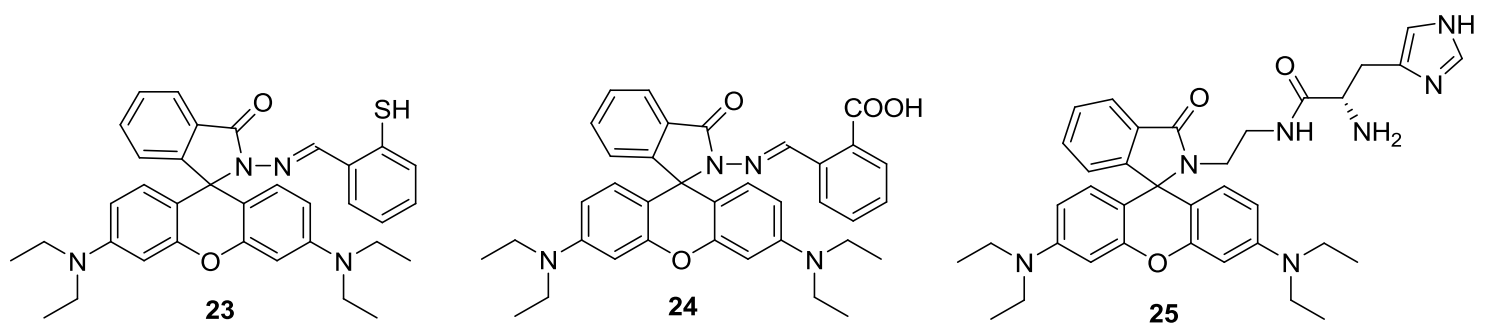

Figure 20. Structures of $\mathrm{Hg}^{2+}$ selective probes 23-25.

On the other hand, a rhodamine-based sensor $\mathbf{2 5}$ bearing a histidine group was also reported as a selective probe for $\mathrm{Hg}^{2+}$ (Figure 20) [46]. Upon the addition of 100 equiv $\mathrm{Hg}^{2+}$ in $0.02 \mathrm{M} \mathrm{pH} 7.4 \mathrm{HEPES}$ : $\operatorname{EtOH}(1: 9, v / v)$, turn-on fluorescence (100-fold) was observed due to the spiro-lactam ring opening. We believe that imidazole nitrogen and two carbonyl oxygenscan provided a nice binding site for $\mathrm{Hg}^{2+}$. Probe 25 was further applied to visualize $\mathrm{Hg}^{2+}$ in HeLa cells.

A rhodamine derivative bearing the selenolactone group 26 was synthesized for the detection of inorganic and organic mercury species (Figure 21) [47]. Through the mercury ion-promoted deselenation reaction, probe $\mathbf{2 6}$ displayed highly selective fluorescent and colorimetric changes for mercury species with high sensitivity in $20 \mathrm{mM}$ HEPES buffer $\left(\mathrm{pH} 7.4,1 \% \mathrm{CH}_{3} \mathrm{CN}\right)$. We then attempted to monitor the mercury species that accumulated in living organisms using 26. Zebrafish has been used as a suitable animal model for the study of fluorescent probes [48]. For our study, adult zebrafish was pre-incubated with $\mathrm{Hg}^{2+}(500 \mathrm{nM})$ or methylmercury $(500 \mathrm{nM})$ and then with probe 26. As shown in Figure 22, strong red fluorescence was observed in the gallbladder, eggs and fin due to the presence of inorganic mercury and methylmercury.

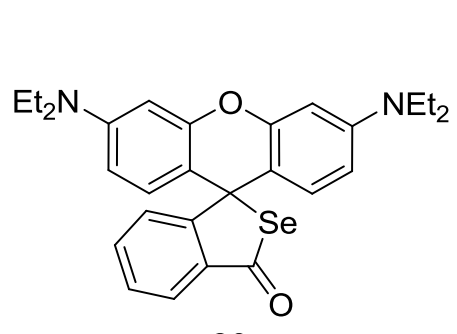

26
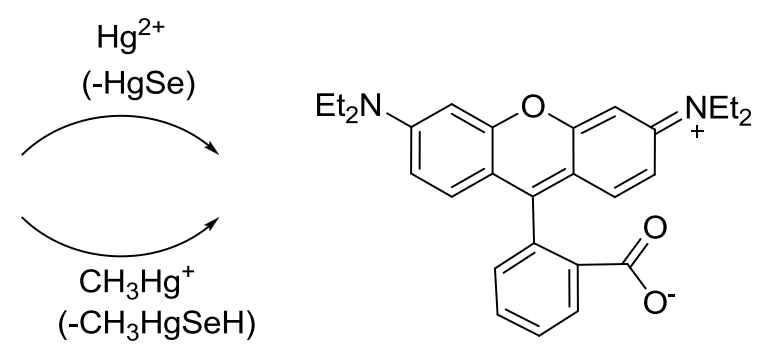

Figure 21. Proposed reaction scheme for probe 26 with $\mathrm{Hg}^{2+}$ and $\mathrm{CH}_{3} \mathrm{Hg}^{+}$. 
a)
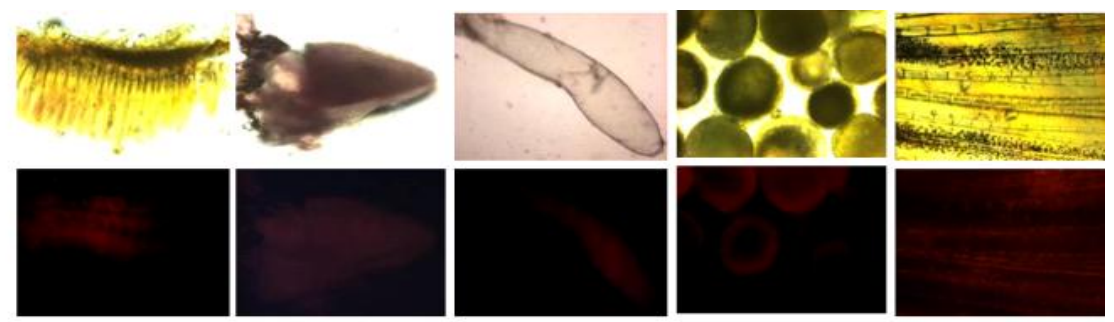

b)
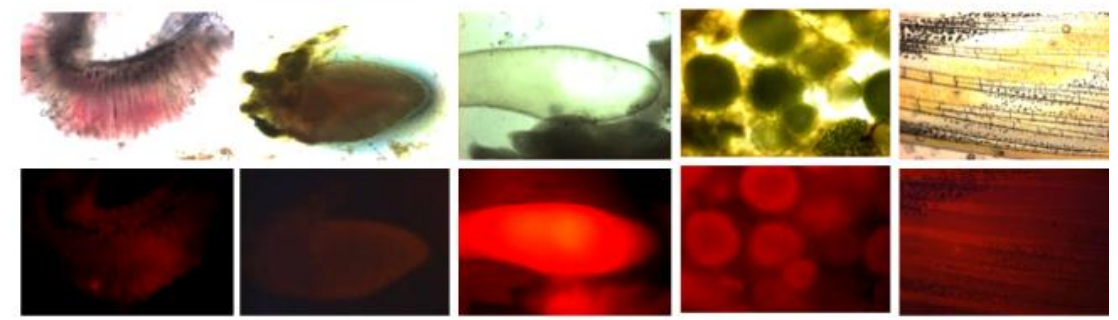

c)
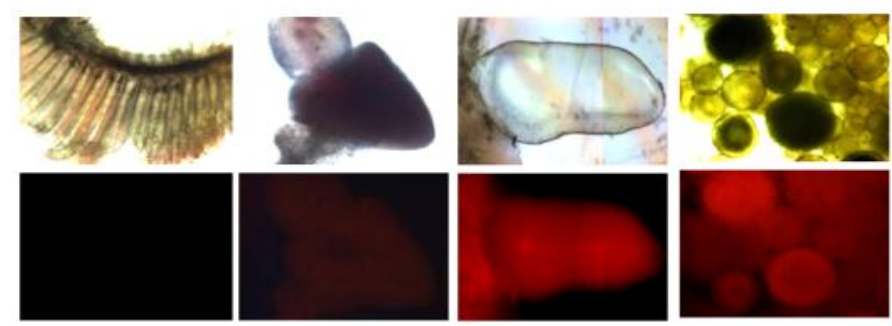

Gills

Heart

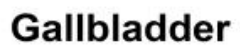

Eggs

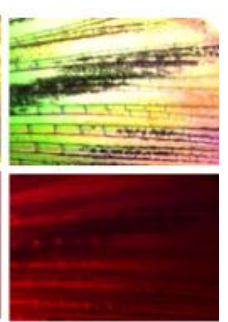

Fin

Figure 22. Images of zebrafish organs treated with $20 \mu \mathrm{M} 26(0.2 \%$ DMSO) and $500 \mathrm{nM}$ $\mathrm{HgCl}_{2}$ or $500 \mathrm{nM} \mathrm{CH} 3 \mathrm{HgCl}$. (a) Images of zebrafish organs treated with $\mathbf{2 6}$ in the absence of $\mathrm{HgCl}_{2}$ or $\mathrm{CH}_{3} \mathrm{HgCl}$; (b) presence of $500 \mathrm{nM} \mathrm{HgCl}_{2}$ or (c) presence of $500 \mathrm{nM} \mathrm{CH} 3 \mathrm{HgCl}$ (upper, merged images; lower, fluorescence images). (Reprinted from reference [47]).

Rhodamine derivative bearing boronic acid (27) was studied as a probe for $\mathrm{Cu}^{2+}$ for the first time (Figure 23) [49]. When $\mathrm{Cu}^{2+}$ was introduced to probe 27 in $20 \mathrm{mM}$ HEPES $\left(0.5 \% \mathrm{CH}_{3} \mathrm{CN}\right)$ at $\mathrm{pH} 7.4$, selective turn-on fluorescence and distinct colorimetric change was observed, which was also attributed to the $\mathrm{Cu}^{2+}$-induced spirolactam ring opening process. Probe 27 was applied to visualize $\mathrm{Cu}^{2+}$ in cells and zebra fish.

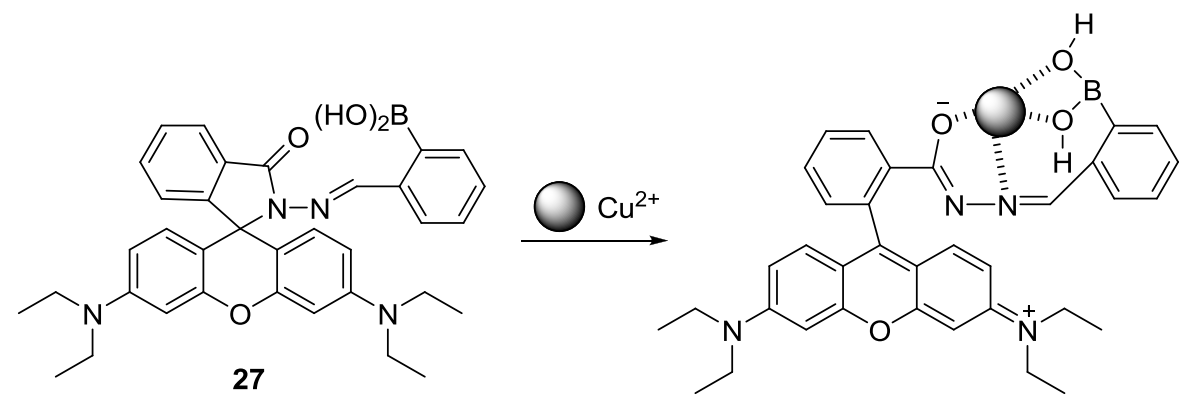

Figure 23. Proposed binding mode of probe 27 with $\mathrm{Cu}^{2+}$.

A reaction based fluorescent probe based on rhodamine-alkyne derivative $\mathbf{2 8}$ was synthesized for the detection of $\mathrm{Au}^{3+}$ (Figure 24) [50]. The addition of $\mathrm{Au}^{3+}$ induced a highly selective turn-on fluorescence and colorimetric change in EtOH-HEPES buffer $(0.01 \mathrm{M}, \mathrm{pH} 7.4)(1: 1, v / v)$. The proposed 
reaction mechanism from the propargylamide moiety of $\mathbf{2 8}$ to the oxazolecarbaldehyde of $\mathbf{2 9}$ is illustrated in Figure 24. The rate constant for the conversion of $\mathbf{2 8}$ to $\mathbf{2 9}$ was reported to be $K_{\text {obs }}=4.5$ $( \pm 0.20) \times 10^{-4} \mathrm{~s}^{-1}$ and the detection limit was calculated as $320 \mathrm{nM}$. In addition, probe 28 was successfully applied to detect $\mathrm{Au}^{3+}$ in the cell.

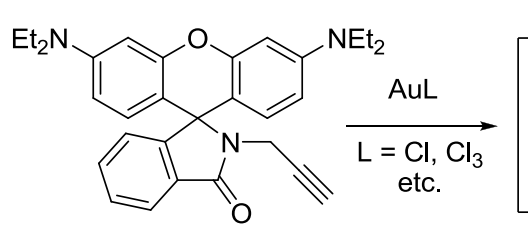

28

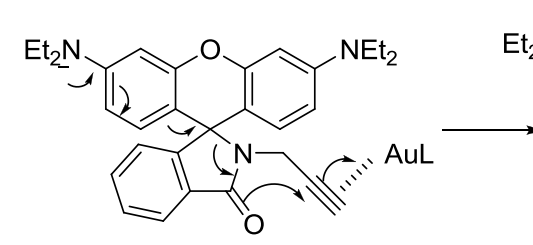<smiles>CCNc1ccc2c(c1)Oc1cc(N(CC)CC)ccc1C2c1ccccc1C1=NCC(CC)O1</smiles>
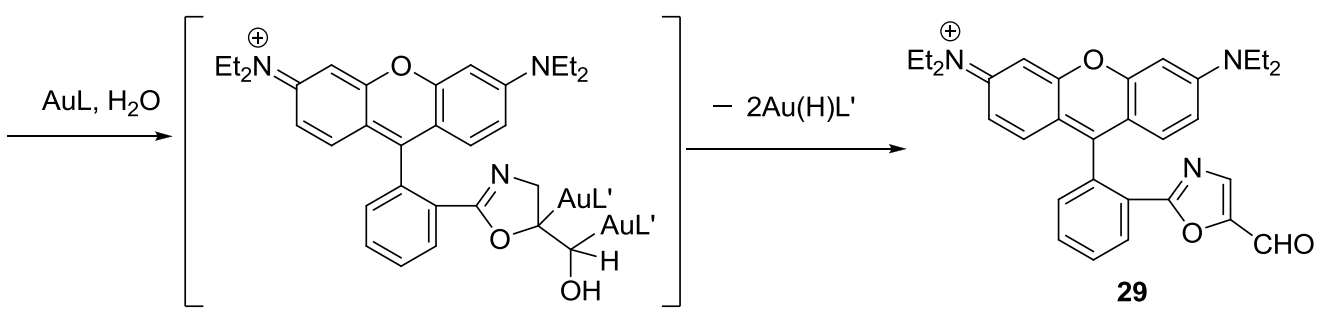

29

Figure 24. Proposed reaction scheme of probe $\mathbf{2 8}$ with $\mathrm{Au}^{3+}$.

A 4-Amino-1,8-naphthalimide derivative bearing an alkyne group (30) was explored as a fluorescent probe for $\mathrm{Au}^{3+}$ (Figures 25 and 26) [51]. The addition of $\mathrm{Au}^{3+}$ induced a distinct color change from yellow to light pink and a large blue shift by about $56 \mathrm{~nm}$ in the emission spectra. The detection limit was calculated to be $8.44 \mu \mathrm{M}$. We observed that surfactants could enhance the reaction rate of probe 30 with $\mathrm{Au}^{3+}$. Probe 30 was also applied to detect $\mathrm{Au}^{3+}$ in HeLa cells and differentiated adipocytes. In particular, probe $\mathbf{3 0}$ showed a unique ability to detect $\mathrm{Au}^{3+}$ in lipid droplets in cells. As shown in Figure 26, the response rates of $\mathbf{3 0}$ with $\mathrm{Au}^{3+}$ in differentiated adipocytes were greater than those in HeLa cells, which is consistent with the rate enhancement in the presence of surfactants.<smiles>C#CCNc1ccc2c3c(cccc13)C(=O)N(CCO)C2=O</smiles>

Figure 25. Structure of the probe 30 . 
a

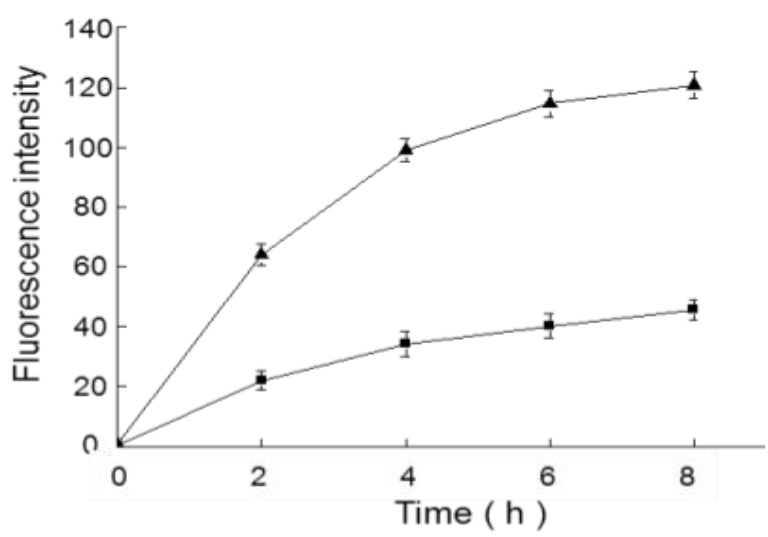

b

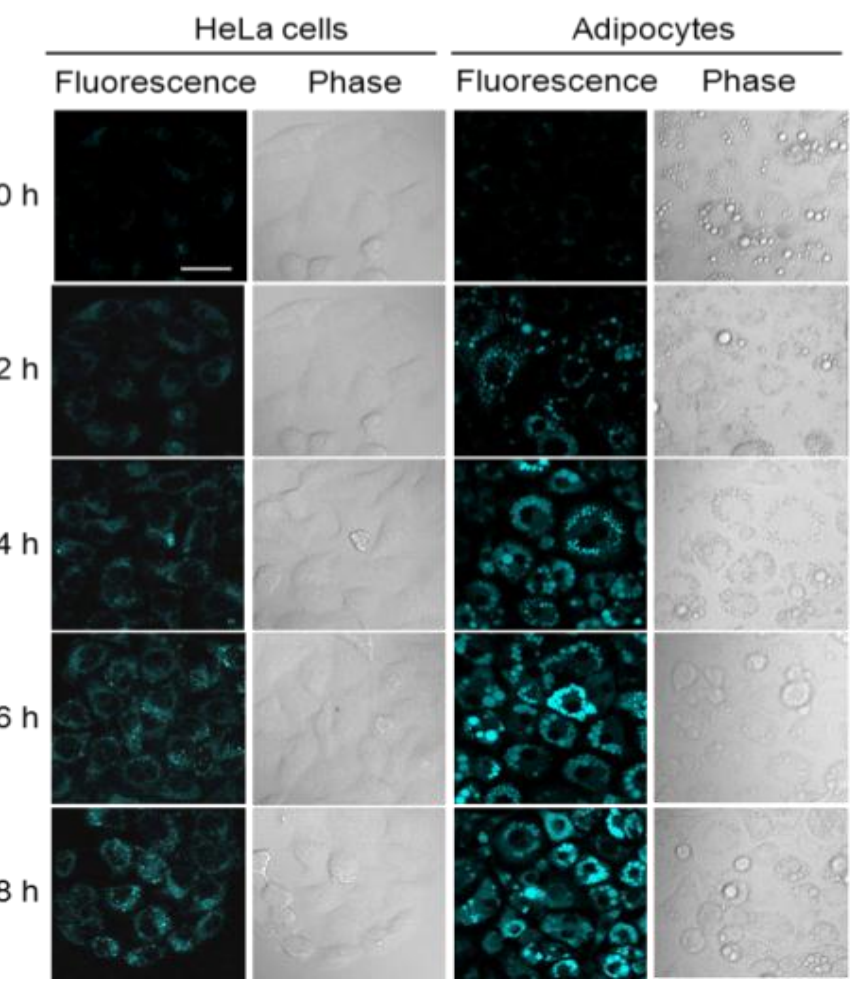

Figure 26. (a) Response rates of $\mathbf{3 0}$ to $\mathrm{Au}^{3+}$ in HeLa cells and differentiated adipocytes. HeLa cells and adipocytes were incubated with $100 \mu \mathrm{M} \mathrm{AuCl}_{3}$ for $2 \mathrm{~h}$ and then with 30 $(20 \mu \mathrm{M})$ for 2, 4, 6, and $8 \mathrm{~h}$ ( $\mathbf{m}$ : HeLa cells, $\boldsymbol{\Delta}$ : adipocytes); (b) Time-dependent fluorescence images of HeLa cells and adipocytes treated with $\mathbf{3 0}$ and $\mathrm{Au}^{3+}$ (scale bar $=20 \mu \mathrm{m}$ ). (Reprinted from reference [51]).

\subsection{Fluorescent Imaging Probes for Cyanide and ATP}

Cyanide ion is a toxic anion. Especially, HCN production by Pseudomonas aeruginosa (PA) is known to be closely related to the pathogenesis of CF lung disease. Accordingly, the detection of cyanide in in vivo systems has become an important issue for bacterial cyanogenesis and CF patients. Cyanide selective fluorescent probes have been actively studied using various design strategies [52].

To develop a new cyanide imaging probe, we firstly synthesized NIR fiuorescent probe sensor 31 (Figure 27) [53]. When $\mathrm{Cu}^{2+}$ was added and the complex $\mathbf{3 1 - \mathbf { C u } ^ { 2 + }}$ was formed, the absorption maximum shifted from 718 to $743 \mathrm{~nm}$ and fluorescence quenching $(748 \mathrm{~nm}$ ) was observed in $20 \mathrm{mM}$ HEPES buffer (pH 7.4, 0.5\% $\mathrm{CH}_{3} \mathrm{CN}$ ). Upon the addition of $\mathrm{CN}^{-}$to $31-\mathbf{C u}^{2+}$, fluorescence emission at $748 \mathrm{~nm}$ was 
recovered since $\mathrm{CN}^{-}$and $\mathrm{Cu}^{2+}$ form the stable $\left[\mathrm{Cu}(\mathrm{CN})_{\mathrm{x}}\right]^{\mathrm{n}-}$. The detection limit for $\mathrm{CN}^{-}$was reported as $5 \mu \mathrm{M}$. Probe 31- $\mathrm{Cu}^{2+}$ was applied to visualize the $\mathrm{CN}^{-}$produced by $P$. aeruginosa (PA) in C. elegans cells. To confirm the bacterial infection in the intestine of the nematodes, a PA14 strain labeled with GFP (green fluorescent protein) was introduced for the $C$. elegans to feed on before the imaging. As shown Figure 28a, neither green nor NIR fluorescence was observed in the nematodes after C. elegans exposure to only E. coli OP50 and probe $31-\mathbf{C u}^{2+}$. On the contrary, when nematodes were exposed to PA14 and the probe, both green and NIR fluorescence were observed, which indicates that the probe can image HCN produced by PA14 in the nematodes (Figure 28b-d). As shown in Figure 29, treatment with a $\beta$-lactam antibiotic, ceftazidime, significantly reduced both the green and NIR fluorescence intensities.

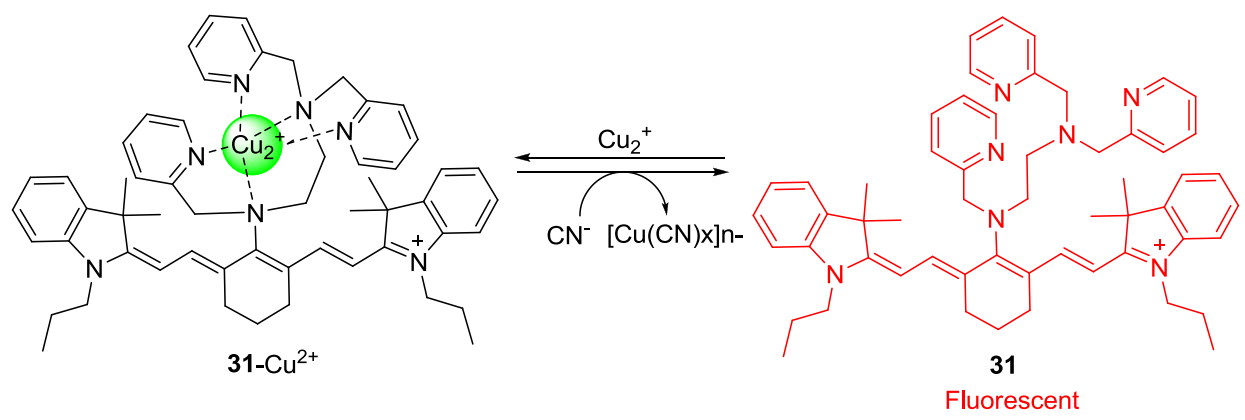

Figure 27. Structure of cyanide selective probe $\mathbf{3 1}$ and $\mathbf{3 1 -} \mathbf{C u}^{2+}$ complex.
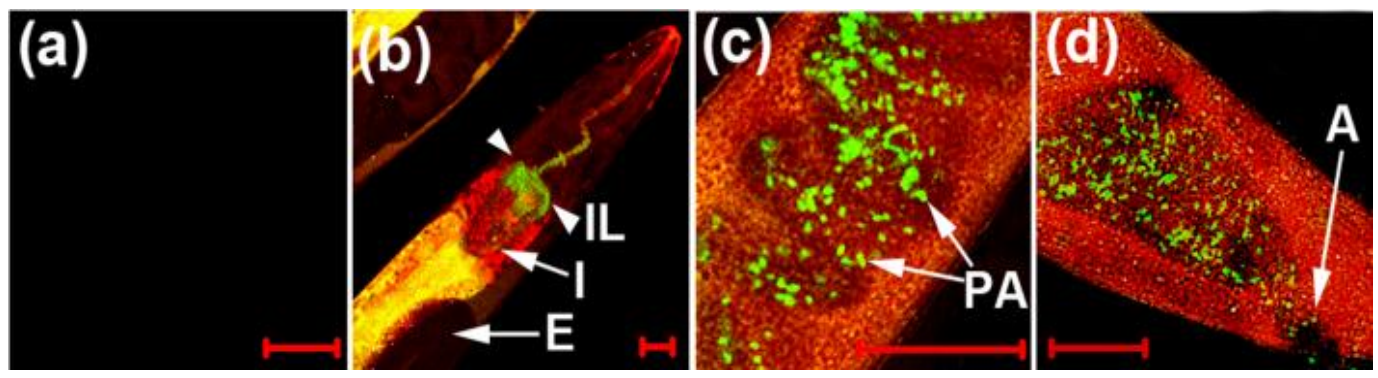

Figure 28. NIR imaging of cyanide in C. elegans infected with a P. aeruginosa strain (PA14) labeled with green fluorescent protein (GFP). Before the imaging, the nematodes fed on either non-infectious E. coli OP50 (a) or GFP-labeled PA14 for 2 days (b-d); (b) the anterior end; (c) the medial part; (d) the posterior end of $C$. elegans. The scale bars represent $20 \mu \mathrm{m}$. (IL = intestinal lumen; I = intestine; $\mathrm{E}=$ eggs; PA = PA14-GFP; $\mathrm{A}=$ anus). (Reprinted from reference [54]).

Imidazolium derivatives serve as host molecules for the recognition of various anions since they can form a unique $(\mathrm{C}-\mathrm{H})^{+}$— anion type ionic hydrogen bond [54-56].

We synthesized an imidazolium receptor bearing two pyrene groups (32) as ATP selective probes, in which a pyrene excimer acts as a signal source and imidazoliums serve as the triphosphate anion receptor (Figure 30) [57]. Among the various nucleoside triphosphates, only ATP showed significant ratiometric changes in its emission. More specifically, only ATP induced an increase in monomer emission at 375 with a sacrifice of excimer emission at $487 \mathrm{~nm}$. We believe this result can be attributed to the different binding mode of ATP compared to the other four nucleoside triphosphate bases: GTP, CTP, UTP and TTP. As shown in Figure 30, ATP can form a characteristic sandwich $\pi$ - $\pi$ stack of 
pyrene-adenine-pyrene while GTP, CTP, UTP and TTP interact with probe 32 from the outside, with the stacked pyrene-pyrene dimer of $\mathbf{3 2}$ resulting in only excimer fluorescence quenching. These different binding modes were proposed based on NMR study and theoretical calculation results. Oligomycin is reported to decrease cellular ATP levels. Probe 32 showed strong blue fluorescence in HeLa cells and the fluorescence was quenched upon the addition of oligomycin.

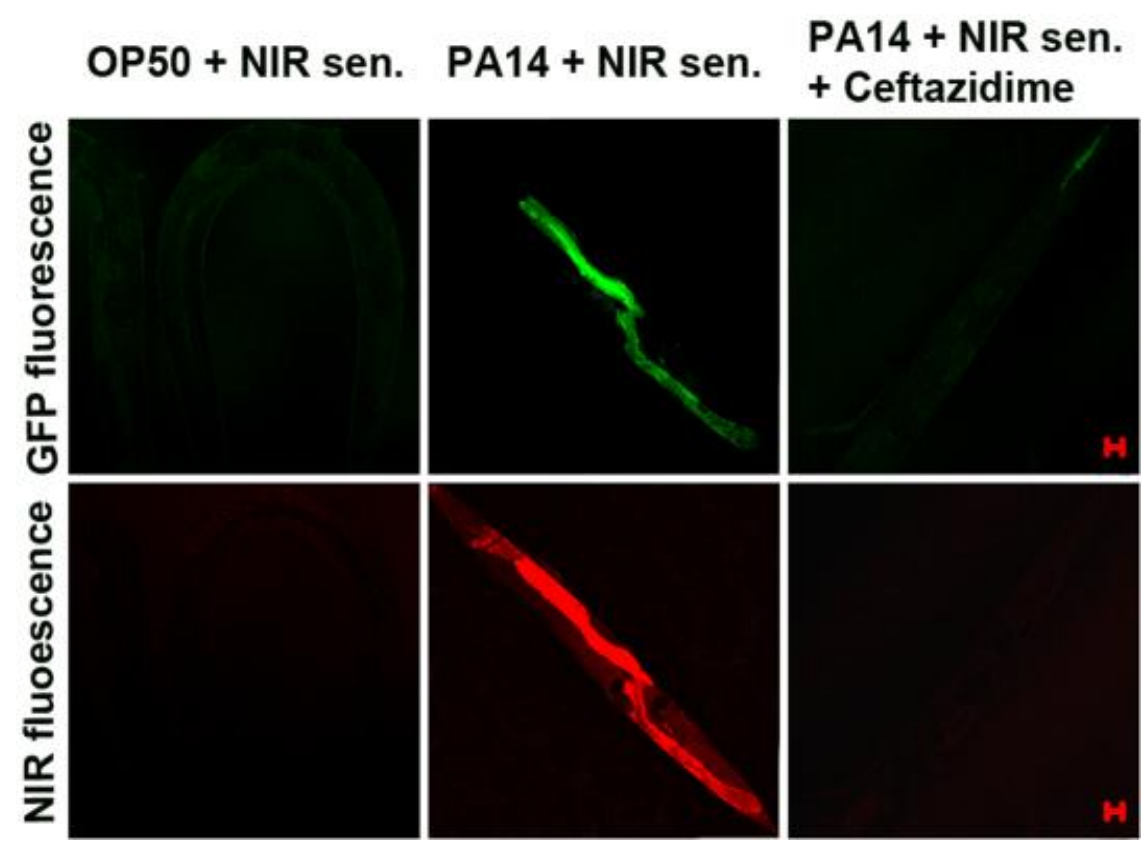

Figure 29. Visualization of antibiotic efficacy against $P$. aeruginosa infection in C. elegans with the NIR sensor. The nematodes fed on GFP-labeled P. aerugionosa (PA14) for two days. They were then incubated with ceftazidime $(200 \mu \mathrm{g} / \mathrm{mL})$ for $2 \mathrm{~h}$ before the in vivo imaging. The scale bars represent $20 \mu \mathrm{m}$. (Reprinted from reference [53]).

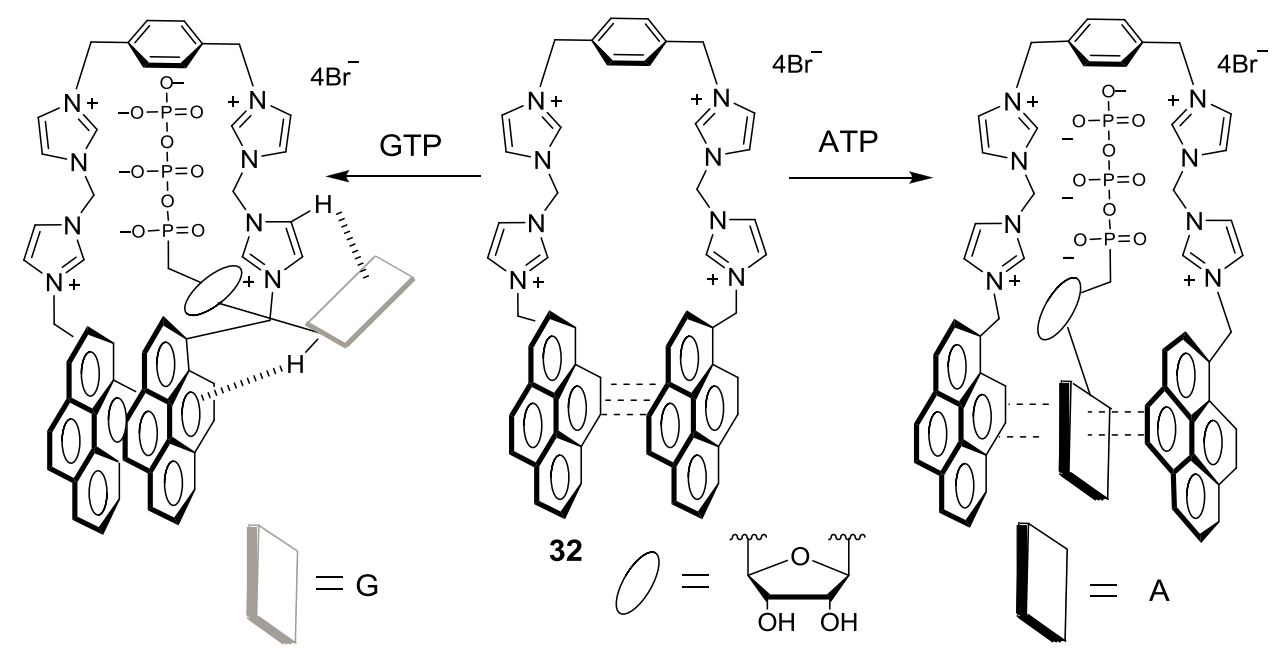

Figure 30. Proposed binding modes of probe 32 with ATP and GTP.

\section{Conclusions and Future Perspectives}

Fluorescence is one of the most powerful tools currently available due to its low detection limit and bioimaging capabilities via confocal microscopy. The application of fluorescent imaging probes for 
various biologically important species has been widely reported in the last decade. In this review, we focused on our exciting contributions in this field. This review was categorized by target analytes, such as biothiols, ROS and RNS, metal ions such as $\mathrm{Zn}^{2+}$ and $\mathrm{Hg}^{2+}$, and finally cyanide and ATP.

Certainly, their application in biology and environmental science has been a strong driving force for the development of fluorescent probes. We believe that intelligent fluorescent probes will be an important research area in the future, and the next generation of functional fluorescent probes will involve imaging and therapeutic agents in vivo [58,59].

\section{Acknowledgments}

This study was supported by the National Research Foundation of Korea (NRF) grant funded by the Korean government (MSIP) (No. 2012R1A3A2048814).

\section{Conflicts of Interest}

The authors declare no conflict of interest.

\section{References}

1. Zhou, X.; Lee, S.; Xu, Z.; Yoon, J. Recent Progress on the Development of Chemosensors for Gases. Chem. Rev. 2015, 115, 7944-8000.

2. Wu, J.; Kwon, B.; Liu, W.; Anslyn, E.V.; Wang, P.; Kim, J.S. Chromogenic/Fluorogenic Ensemble Chemosensing Systems. Chem. Rev. 2015, 115, 7893-7943.

3. Shamirian, A.; Ghai, A.; Snee, P.T. QD-Based FRET Probes at a Glance. Sensors 2015, 15, 13028-13051.

4. Yin, J.; Hu, Y.; Yoon, J. Fluorescence probes and bioimaging: Alkali metals, alkaline earth metals and protons. Chem. Soc. Rev. 2015, 44, 4619-4644.

5. Miller, E.W.; Chang, C.J. Fluorescent probes for nitric oxide and hydrogen peroxide in cell signaling. Curr. Opin. Chem. Biol. 2007, 11, 620-625.

6. Guo, Z.; Shin, I.; Yoon, J. Recognition and Sensing of Various Species Using Boronic Acid Derivatives. Chem. Commun. 2012, 48, 5956-5967.

7. Thomas, J.A. Optical imaging probes for biomolecules: An introductory perspective. Chem. Soc. Rev. 2015, 44, 4494-4500.

8. Zhou, Y.; Zhang, J.F.; Yoon, J. Fluorescent and Colorimetric Chemosensors for Detection of Fluoride Ion. Chem. Rev. 2014, 114, 5511-5571.

9. Lee, S.; Yuen, K.K.Y.; Jolliffe, K.A.; Yoon, J. Fluorescent and Colorimetric Chemosensors for Pyrophosphate. Chem. Soc. Rev. 2015, 44, 1749-1762.

10. Chen, X.; Pradhan, T.; Wang, F.; Kim, J.S.; Yoon, J. Fluorescent Chemosensors Based on Spiroring-Opening of Xanthenes and Related Derivatives. Chem. Rev. 2012, 112, 1910-1956.

11. Guo, Z.; Park, S.; Yoon, J.; Shin, I. Recent Progress on Near-Infrared Fluorescent Probes for Bioimaging Applications. Chem. Soc. Rev. 2014, 43, 16-29.

12. Amiot, C.L.; Xu, S.; Liang, S.; Pan, L.; Zhao, J.X. Near-Infrared Fluorescent Materials for Sensing of Biological Targets. Sensors 2008, 8, 3082-3105. 
13. Kim, H.M.; Cho, B.R. Two-Photon Probes for Intracellular Free Metal Ions, Acidic Vesicles, and Lipid Rafts in Live Tissues. Acc. Chem. Res. 2009, 42, 863-872.

14. Zhang, X.; Yin, J.; Yoon, J. Recent Advances in Development of Chiral Fluorescent and Colorimetric Sensors. Chem. Rev. 2014, 114, 4918-4959.

15. De Silva, A.P.; Gunaratne, H.Q.N.; Gunnlaugsson, T.A.; Huxley, T.M.; McCoy, C.P.; Rademacher J.T.; Rice, T.E. Signaling Recognition Events with Fluorescent Sensors and Switches. Chem. Rev. 1997, 97, 1515-1566.

16. Czarnik, A.W. Chemical Communication in Water Using Fluorescent Chemosensors. Acc. Chem. Res. 1994, 27, 302-308.

17. Yoon, J.; Czarnik, A.W. Fluorescent Chemosensors of Carbohydrates. A Means of Chemically Communicating the Binding of Polyols in Water Based on Chelation-Enhanced Quenching. J. Am. Chem. Soc. 1992, 114, 5874-5875.

18. Tang, Y.; Lee, D.; Wang, J.; Li, G.; Lin, W.; Yoon, J. Development of fluorescent probes based on protection-deprotection of aldehyde, hydroxyl, and amino functional groups for biological imaging. Chem. Soc. Rev. 2015, 44, 5003-5015.

19. Jun, M.E.; Roy, B.; Ahn, K.H. Turn-on fluorescent sensing with reactive probes. Chem. Commun. 2011, 47, 7583-7601.

20. Yeung, M.C.-L.; Yam, V.W.-W. Luminescent cation sensors: From host-guest chemistry, supramolecular chemistry to reaction-based mechanisms. Chem. Soc. Rev. 2015, 44, 4192-4202.

21. Jung, H.S.; Chen, X.; Kim, J.S.; Yoon, J. Recent progress in luminescent and colorimetric chemosensors for detection of thiols. Chem. Soc. Rev. 2013, 42, 6019-6031.

22. Chen, X.; Ko, S.-K.; Kim, M.J.; Shin, I.; Yoon, J. A Thiol-Specific Fluorescent Probe and Its Application for Bioimaging. Chem. Commun. 2010, 46, 2751-2753.

23. Yang, X.; Guo, Y.; Strongin, R.M. Conjugate Addition/Cyclization Sequence Enables Selective and Simultaneous Fluorescence Detection of Cysteine and Homocysteine. Angew. Chem. Int. Ed. 2011, 50, 10690-10693.

24. Guo, Z.; Nam, S.W.; Park, S.; Yoon, J. A Highly Selective Ratiometric Near-Infrared Fluorescent Cyanine Sensor for Cysteine with Remarkable Shift and Its Application Bioimaging. Chem. Sci. 2012, 3, 2760-2765.

25. Lee, H.Y.; Choi, Y.P.; Kim, S.K.; Yoon, T.; Guo, Z.; Swamy, K.M.K.; Kim, G.; Lee, J.Y.; Shin, I.; Yoon, J. Selective Homocysteine Turn-on Fluorescent Probes and Their Bioimaging Applications. Chem. Commun. 2014, 50, 6967-6969.

26. Hu, Y.; Heo, C.H.; Kim, G.; Jun, E.J.; Yin, J.; Kim, H.M.; Yoon, J. One-Photon and Two-Photon Sensing of Biothiols Using A Bis-Pyrene-Cu(II) Ensemble and Its Application to Image GSH in the Cells and Tissues. Anal. Chem. 2015, 87, 3308-3313.

27. Yin, J.; Kwon, Y.; Kim, D.; Lee, D.; Kim, G.; Hu, Y.; Ryu, J.-H.; Yoon, J. A Cyanine Based Fluorescence Probe for Highly Selective Detection of Glutathione in Cell Cultures and Live Mice Tissues. J. Am. Chem. Soc. 2014, 136, 5351-5358.

28. Lee, D.; Kim, G.; Yin, J.; Yoon, J. Aryl-thioether substituted nitrobenzothiadiazole probe for selective detection of cysteine and homocysteine. Chem. Commun. 2015, 51, 6518-6520.

29. Chen, X.; Tian, X.; Shin, I.; Yoon, J. Fluorescent and luminescent probes for detection of reactive oxygen and nitrogen species. Chem. Soc. Rev. 2011, 40, 4783-4804. 
30. Chen, X.; Lee, K.-A.; Ha, E.-M.; Lee, K.M.; Seo, Y.Y.; Choi, H.K.; Kim, H.N.; Kim, M.J.; Cho, C.-S.; Lee, S.Y.; et al. A specific and sensitive method for detection of hypochlorous acid for the imaging of microbe-induced $\mathrm{HOCl}$ production. Chem. Commun. 2011, 47, 4373-4375.

31. Xu, Q.; Lee, K.-A.; Lee, S.; Lee, K.M.; Lee, W.-J.; Yoon, J. A Highly Specific Fluorescent Probe for Hypochlorous Acid and Its Application in Imaging Microbe-Induced HOCl Production. J. Am. Chem. Soc. 2013, 135, 9944-9949.

32. Xu, Q.; Heo, C.H.; Kim, G.; Lee, H.W.; Kim, H.M.; Yoon, J. Development of Imidazoline-2Thiones Based Two-Photon Fluorescence Probes for Imaging Hypochlorite Generation in a Co-Culture System. Angew. Chem. Int. Ed. 2015, 54, 4890-4894.

33. Sun, X.; Xu, Q.; Kim, G.; Flower, S.E.; Lowe, J.P.; Yoon, J.; Fossey, J.S.; Qian, X.; Bull, S.D.; James, T.D. A water-soluble boronate-based fluorescent probe for the selective detection of peroxynitrite and imaging in living cells. Chem. Sci. 2014, 5, 3368-3373.

34. Zhou, X.; Kwon, Y.; Kim, G.; Ryu, J.-H.; Yoon, J. A ratiometric fluorescent probe based on a coumarin-hemicyanine scaffold for sensitive and selective detection of endogenous peroxynitrite. Biosens. Bioelectron. 2015, 64, 285-291.

35. Kim, D.; Kim, G.; Nam, S.-J.; Yin, J.; Yoon, J. Visualization of Endogenous and Exogenous Hydrogen Peroxide Using A Lysosome-Targetable Fluorescent Probe. Sci. Rep. 2015, 5, 8488.

36. Xu, Z.; Yoon, J.; Spring, D.R. Fluorescent Chemosensors for $\mathrm{Zn}^{2+}$. Chem. Soc. Rev. 2010, 39, 1996-2006.

37. Xu, Z.; Kim, G.-H.; Han, S.J.; Jou, M.J.; Lee, C.; Shin, I.; Yoon, J. An NBD-based colorimetric and fluorescent chemosensor for $\mathrm{Zn}^{2+}$ and its use for detection of intracellular zinc ions. Tetrahedron 2009, 65, 2307-2312.

38. Xu, Z.; Baek, K.-H.; Kim, H.N.; Cui, J.; Qian, X.; Spring, D.R.; Shin, I.; Yoon, J. Zn ${ }^{2+}$-Triggered Amide Tautomerization Produces a Highly $\mathrm{Zn}^{2+}{ }_{-}$Selective, Cell-Permeable and Ratiometric Fluorescent Sensor. J. Am. Chem. Soc. 2010, 132, 601-610.

39. Guo, Z.; Kim, G.-H.; Shin, I.; Yoon, J. A Cyanine-Based Fluorescent Sensor for Detecting Endogenous Zinc Ions in Live Cells and Organisms. Biomaterials 2012, 33, 7818-7827.

40. Guo, Z.; Kim, G.-H.; Yoon, J.; Shin, I. Synthesis of a highly $\mathrm{Zn}^{2+}$-selective cyanine-based probe and its use for tracing endogenous zinc ions in cells and organisms. Nat. Protocol. 2014, 9, 1245-1254.

41. Palmiter, R.D. The elusive function of metallothioneins. Proc. Natl. Acad. Sci. USA 1998, 95, 8428-8430.

42. Kim, H.N.; Ren, W.X.; Kim, J.S.; Yoon, J. Fluorescent and Colorimetric Sensors for Detection of Lead, Cadmium, and Mercury Ions. Chem. Soc. Rev. 2012, 41, 3210-3244.

43. Park, S.; Kim, W.; Swamy, K.M.K.; Jung, J.Y.; Kim, G.; Kim, Y.; Kim, S.-J.; Yoon, J. Rhodamine Hydrazone Derivatives Bearing Thiophene Group as Fluorescent and Colorimetric Chemosensors for $\mathrm{Hg}^{2+}$. Dyes Pigm. 2013, 99, 323-328.

44. Kwon, J.Y.; Jang, Y.J.; Lee, Y.J.; Kim, K.-M.; Seo, M.-S.; Nam, W.; Yoon, J. A Highly Selective Fluorescent Chemosensor for $\mathrm{Pb}^{2+}$. J. Am. Chem. Soc. 2005, 127, 10107-10111.

45. Kim, H.N.; Nam, S.-W.; Swamy, K.M.K.; Jin, Y.; Chen, X.; Kim, Y.; Kim, S.-J.; Park, S.; Yoon, J. Rhodamine Hydrazone Derivatives as $\mathrm{Hg}^{2+}$ Selective Fluorescent and Colorimetric Chemosensors and Their Applications to Bioimaging and Microfluidic System. Analyst 2011, 136, 1339-1343. 
46. Kwon, S.K.; Kim, H.N.; Rho, J.H.; Swamy, K.M.K.; Shanthakumar, S.M.; Yoon, J. Rhodamine Derivative Bearing Histidine Binding Site as a Fluorescent Chemosensor for $\mathrm{Hg}^{2+}$. Bull. Korean Chem. Soc. 2009, 30, 719-721.

47. Chen, X.; Baek, K.-H.; Kim, Y.; Kim, S.-J.; Shin, I.; Yoon, J. A Selenolactone-Based Fluorescent Chemodosimeter to Monitor Mercury/ Methylmercury Species in vitro and in vivo. Tetrahedron 2010, 66, 4016-4021.

48. Ko, S.-K.; Chen, X.; Yoon, J.; Shin, I. Zebrafish as a good vertebrate model for molecular imaging using fluorescent probes. Chem. Soc. Rev. 2011, 40, 2120-2130.

49. Swamy, K.M.K.; Ko, S.-K.; Kwon, S.K.; Lee, H.N.; Mao, C.; Kim, J.-M.; Lee, K.-H.; Kim, J.; Shin, I.; Yoon, J. Boronic Acid-Linked Fluorescent and Colorimetric Probes for Copper Ions. Chem. Commun. 2008, 5915-5917.

50. Jou, M.J.; Chen, X.; Swamy, K.M.K.; Kim, H.N.; Kim, H.-J.; Lee, S.-G.; Yoon, J. Highly Selective Fluorescent Probe for $\mathrm{Au}^{3+}$ Based on Cyclization of Propargylamide. Chem. Commun. 2009, 14, 7218-7220.

51. Choi, J.Y.; Kim, G.-H.; Guo, Z.; Swamy, K.M.K.; Lee, H.Y.; Pai, J.; Shin, S.; Shin, I.; Yoon, J. Highly Selective Ratiometric Fluorescent Probe for $\mathrm{Au}^{3+}$ and Its Application to Bioimaging. Biosens. Bioelectron. 2013, 49, 438-441.

52. Wang, F.; Wang, L.; Chen, X.; Yoon, J. Recent progress in the development of fluorometric and colorimetric chemosensors for detection of cyanide ion. Chem. Soc. Rev. 2014, 43, 4312-4324.

53. Chen, X.; Nam, S.-W.; Kim, G.-H.; Song, N.; Jeong, Y.; Shin, I.; Kim, S.K.; Kim, J.; Park, S.; Yoon, J. A Near-Infrared Fluorescent Sensor for Detection of Cyanide in Aqueous Solution and Its Application for Bioimaging. Chem. Commun. 2010, 46, 8953-8955.

54. Xu, Z.; Kim, S.K.; Yoon, J. Revisit to Imidazolium Receptors for the Recognition of Anions: Highlighted Research During 2006-2009. Chem. Soc. Rev. 2010, 39, 1457-1466.

55. Kim, S.K.; Singh, N.J.; Kwon, J.; Hwang, I.-C.; Park, S.J.; Kim, K.S.; Yoon, J. Fluorescent Imidazolium Receptors for the Recognition of Pyrophosphate. Tetrahedron 2006, 62, 6065-6072.

56. Kim, S.K.; Kang, B.-G.; Koh, H.S.; Yoon, Y.J.; Jung, S.J.; Jeong, B.; Lee, K.-D.; Yoon, J. A New ImidazoliumCavitand for the Recognition of Dicarboxylates. Org. Lett. 2004, 6, 4655-4658.

57. Xu, Z.; Singh, N.J.; Lim, J.; Pan, J.; Kim, H.N.; Park, S.; Kim, K.S.; Yoon, J. Unique Sandwich Stacking of Pyrene-Adenine-Pyrene for Selective and Ratiometric Fluorescent Sensing of ATP at Physiological pH. J. Am. Chem. Soc. 2009, 131, 15528-15533.

58. Kolemen, S.; Işı1k, M.; Kim, G.M.; Kim, D.; Geng, H.; Buyuktemiz, M.; Karatas, T.; Zhang, X.-F.; Dede, Y.; Yoon, J.; et al. Intracellular Modulation of Excited-State Dynamics in a Chromophore Dyad: Differential Enhancement of Photocytotoxicity Targeting Cancer Cells. Angew. Chem. Int. Ed. 2015, 54, 5340-5344.

59. Kim, E.-J.; Bhuniya, S.; Lee, H.; Kim, H.M.; Cheong, C.; Maiti, S.; Hong, K.S.; Kim, J.S. An Activatable Prodrug for the Treatment of Metastatic Tumor. J. Am. Chem. Soc. 2014, 136, 13888-13894.

(C) 2015 by the authors; licensee MDPI, Basel, Switzerland. This article is an open access article distributed under the terms and conditions of the Creative Commons Attribution license (http://creativecommons.org/licenses/by/4.0/). 